\title{
Relating Performance of Thin-Film Composite Forward Osmosis Membranes to Support Layer Formation and Structure
}

\author{
Submitted to \\ Journal of Membrane Science
}

October 1, 2010

\begin{abstract}
Alberto Tiraferri, Ngai Yin Yip, William A. Phillip, Jessica D. Schiffman, and Menachem Elimelech*
\end{abstract}

Department of Chemical and Environmental Engineering Yale University

P.O. Box 208286

New Haven, CT 06520-8286, USA

* Corresponding Author: phone +1 (203) 432 2789; E-mail: menachem.elimelech@yale.edu 


\begin{abstract}
Osmotically-driven membrane processes have the potential to treat impaired water sources, desalinate sea/brackish waters, and sustainably produce energy. The development of a membrane tailored for these processes is essential to advancing the technology to the point that it is commercially viable. Here, a systematic investigation of the influence of thin-film composite membrane support layer structure on forward osmosis performance is conducted. The membranes consist of a selective polyamide active layer formed by interfacial polymerization on top of a polysulfone support layer fabricated by phase separation. By systematically varying the conditions used during the casting of the polysulfone layer, an array of support layers with differing structures were produced. The role that solvent quality, dope polymer concentration, fabric layer wetting, and casting blade gate height play in the support layer structure formation was investigated. Using a $1 \mathrm{M} \mathrm{NaCl}$ draw solution and a deionized water feed, water fluxes ranging from 4 to around $25 \mathrm{~L} \mathrm{~m}^{-2} \mathrm{~h}^{-1}$ with consistently high salt rejection (>95.5\%) were produced. The relationship between membrane structure and performance was analyzed. This study confirms the hypothesis that the optimal forward osmosis membrane consists of a mixedstructure support layer, where a thin sponge-like layer sits on top of highly porous macrovoids. Both the active layer transport properties and the support layer structural characteristics need to be optimized in order to fabricate a high performance forward osmosis membrane.
\end{abstract}

Keywords: Forward osmosis; Thin-film composite; Porous support; Polysulfone support layer; Support structure; Support formation; Membrane structure; Internal concentration polarization

\title{
1. Introduction
}

Osmotically-driven membrane processes utilize an osmotic pressure difference, which is generated when a semi-permeable membrane separates a dilute feed solution from a more concentrated draw solution, to drive the permeation of water from the feed solution to the draw solution. These processes have the potential to sustainably produce clean drinking water or electric power [1]. Forward osmosis (FO), a subset of osmotically-driven membrane processes is 
appealing because it requires no applied hydraulic pressure and has a low membrane fouling propensity [2]. Because of these benefits, FO is attracting attention as a new technology to augment water supplies using non-traditional sources. The potential of this technology has been demonstrated in a variety of applications, such as desalination [3, 4], wastewater reclamation [57], industrial wastewater treatment [3, 8], brine concentration [9], osmotic membrane bioreactors [10], liquid food processing [3, 11, 12], and protein concentration [13].

Thus far, one of the major obstacles to the implementation of FO has been the lack of a membrane designed specifically for the process. Such a membrane should reject dissolved solutes, produce high permeate fluxes, be compatible with the selected draw solution, and withstand the mechanical stresses generated during operation. No commercially available membrane currently possesses all of these required characteristics. For example, commercial asymmetric cellulose triacetate membranes are chemically stable only in a small $\mathrm{pH}$ window between 4 and $6[14,15]$. The commercial standard for reverse osmosis (RO) desalination of seawater, thin-film composite (TFC) polyamide (PA) membranes, generate low water fluxes when used in FO, as a result of internal concentration polarization (ICP).

ICP occurs because the porous support layer acts as an unstirred diffusive boundary layer. As water permeates across the membrane active layer, the draw solution at the active surface of the membrane is diluted while the diffusion of draw solute from the bulk solution works to restore the concentration at the active layer surface. These competing processes result in a draw solute concentration profile where the concentration at the active layer interface is lower than the bulk concentration, thus reducing the osmotic pressure difference across the active layer [16].

The ideal support layer for FO is very thin, highly porous, and has little tortuosity, thereby providing a short path from the bulk draw solution to the active surface of the membrane (i.e. a thin boundary layer). The dense and thick porous support layer of current commercial TFC RO membranes provides a significant resistance to diffusion, resulting in severe ICP that drastically reduces the water flux. Decreasing the effective thickness of the unstirred boundary layer is essential to minimizing the adverse effects of ICP and to enhancing membrane performance. This characteristic can be achieved by tailoring the structure of the thin-film composite membrane support layer. 
During membrane support fabrication by a nonsolvent induced phase separation process, nonsolvent permeates into the film of polymer solution while solvent leaves the film. As a result of this exchange, the composition of the polymer film changes until the stability limit is reached, where the solution phase separates into a polymer-rich and a polymer-poor phase. These two phases eventually form the polymer matrix and pores, respectively [14, 17].

Numerous efforts have been made to understand the membrane structure formation mechanism during phase separation. Although theories attempting to quantify or qualify the phenomenon are still being debated, it is accepted that the thermodynamic state and kinetic properties of the system, as well as how they vary during processing, govern the structure formation pathway, and thus, the resulting morphology of a membrane made by phase separation [17-19]. This pathway depends on the temperature, the composition of the casting solution, the composition of the nonsolvent bath, and the surrounding atmosphere. By systematically varying some of these parameters, it is possible to understand how the processing conditions affect the final membrane structure.

Recently, we have demonstrated the fabrication of a TFC membrane tailored for FO operation in a lab-scale setting, exhibiting flux and selectivity performance superior to commercially available FO membranes [20]. This structure was achieved through rational modifications of the membrane casting procedure. The resulting TFC membrane comprises a PA active layer fabricated via interfacial polymerization on top of a porous polysulfone support layer. The modified fabrication procedures allowed the formation of a highly porous support of a finger-like morphology, consisting of macrovoids that span most of the support layer thickness. These macrovoids reduce the resistance to diffusion compared to denser morphologies [20]. In addition, it was proposed that having a thin layer with a sponge-like morphology at the top of the support layer is beneficial to the design of high performance FO membranes [20, 21]. The sponge-like layer facilitates the formation of an integral PA active layer, resulting in membranes with higher intrinsic water permeability and improved selectivity [14]. Therefore, the optimal support layer structure reduces ICP without compromising the integrity of the PA active layer [20]. This desired membrane structure was created by using a mixed solvent system and low polymer casting solution concentration during the phase separation step of support layer fabrication [20]. 
Understanding how membrane structural characteristics influence performance is crucial to further development of membranes designed for FO processes. Here we provide the first systematic investigation on the relationship between membrane support layer structure and FO membrane performance. TFC membranes were fabricated following a two-step procedure: casting of a polysulfone (PSf) support layer onto a PET fabric by phase separation followed by the formation of a PA thin film on top of the PSf support layer through interfacial polymerization. Casting parameters for the PSf formation step were systematically varied. Specifically, the roles of solvent composition, dope polymer concentration, substrate fabric wetting, and the gate height of the casting blade were investigated. The resulting TFC membranes were evaluated in RO and FO operations to determine the membrane transport and structural characteristics. The relationship between these characteristics and the FO membrane performance are evaluated and discussed.

\section{Materials and Methods}

\subsection{Materials and Chemicals}

Polysulfone (PSf) beads ( $\mathrm{M}_{\mathrm{n}}$ : 22,000 Da), 1-methyl-2-pyrrolidinone (NMP, anhydrous, 99.5\%), $N$ - $N$-dimethylformamide (DMF, anhydrous, 99.8\%), 1,3-phenylenediamine (MPD, >99\%), and 1,3,5-benzenetricarbonyl trichloride (TMC, 98\%) were used as received (Sigma-Aldrich, St. Louis, MO). TMC was dispersed in Isopar-G, a proprietary non-polar organic solvent (Univar, Redmond, WA). A commercial polyester non-woven fabric (PET, Grade 3249, Ahlstrom, Helsinki, Finland) was used as a backing layer for the PSf supports. The PET fabric is thinner (40 $\mu \mathrm{m})$ and has a more open structure than the typically employed fabric layers [20]. For the membrane performance tests, sodium chloride ( $\mathrm{NaCl}$, crystals, ACS reagent) from J.T. Baker (Phillipsburg, NJ) was dissolved in deionized water (DI) obtained from a Milli-Q ultrapure water purification system (Millipore, Billerica, MA).

\subsection{Polysulfone Porous Support Fabrication}

2.2.1. Phase Inversion Procedure for Casting of the Polysulfone Support Layer 
PSf was dissolved in the solvent or solvent mixture (Figure 1) by stirring at room temperature $\left(23^{\circ} \mathrm{C}\right)$ for $8 \mathrm{~h}$ and then stored in a desiccator for at least $15 \mathrm{~h}$ prior to casting. To begin casting the membrane, the thin, low-density PET fabric was attached to a clean glass plate using laboratory adhesive tape. The PET fabric was then wet with solvent and any excess solvent that pooled on the surface of the fabric was removed using an air knife. The PSf solution was drawn down the PET fabric using a casting knife (Gardco, Pompano Beach, FL) with an adjustable gate height fixed at $250 \mu \mathrm{m}$ ( 10 mils). The whole composite was immediately immersed in a precipitation bath containing $3 \mathrm{wt} \%$ solvent in DI at room temperature to initiate the nonsolvent induced phase separation [14, 22]. The solvent composition incorporated into the precipitation bath was identical to that used for the preparation of casting dope solution. The support membrane was allowed to sit in the precipitation bath for $10 \mathrm{~min}$, at which point it was transferred to a DI bath for storage until PA formation.

Figure 1. Summary of the different recipes employed in the fabrication of the PSf support layers. The columns represent different NMP and DMF mixtures, with the DMF concentration increasing from left to right. Namely, the DMF concentrations are 0, 25, 50, 75, and $100 \mathrm{wt} \%$ (based only on the solvent masses) for columns 1 through 5, respectively. The rows represent different PSf concentrations increasing down the column. The PSf concentrations are 9, 12, 15, and $18 \mathrm{wt} \%$ for rows 1 through 4, respectively. The investigated recipes are highlighted in grey and crossed. The cell corresponding to 18 wt \% PSf concentration in 100\% DMF is crossed using a dash line because the related data is incomplete as explained in the discussion.

To investigate the influence of the fabric wetting pretreatment on resultant membrane structure and performance, some membranes were cast without wetting the PET fabric. These specific membranes were cast with 12 and 15 wt \% PSf in 100\% NMP solvent. To examine the

role of initial PSf film thickness on resultant membrane structure and performance, some membranes were cast using a different gate height of the casting knife, namely $500 \mu \mathrm{m}$ ( 20 mils). These membranes were fabricated from solutions comprising 12 wt \% PSf in 100\% NMP solvent.

\subsubsection{Phase inversion casting solutions}

A range of different porous support structures was produced based on a systematic array of varied phase inversion casting solutions (highlighted cells in Figure 1). The effect of polymer 
concentration was studied by varying the weight percent of PSf from 9 to $18 \mathrm{wt} \%$ in both NMP and DMF solvents. To investigate the influence of solvent composition, the proportion of NMP and DMF used to prepare the solvent mixture was varied while keeping PSf concentration constant at 12 wt \%.

\subsubsection{Determination of the cloud point}

The cloud point was determined by a titrimetric method using 12 wt \% PSf solutions at room temperature. Polymer solutions were dissolved in a pure or mixed solvent and placed in a sealable bottle. The solutions were stirred while pure nonsolvent (DI water) was added until the polymer solution became irreversibly turbid as determined by visual detection. The cloud point was calculated as the mass ratio of nonsolvent to total polymer solution plus the nonsolvent [23].

\subsection{Polyamide Active Layer Fabrication}

The PA active layer was formed on top of the hand-cast PSf support membranes via interfacial polymerization, following the procedure outlined in our previous publication [20]. Briefly, PA was fabricated by first immersing the PSf support in a 3.4 wt \% aqueous MPD solution for $120 \mathrm{~s}$. An air knife was then used to remove the excess solution from the membrane surface. Next, the MPD-saturated support membrane was immersed into a $0.15 \mathrm{wt} \%$ TMC in Isopar-G solution for 60 s. During this contacting step the ultra-thin PA layer formed. The composite membranes were then cured in DI at $95^{\circ} \mathrm{C}$ for $120 \mathrm{~s}$, rinsed with a $200 \mathrm{ppm} \mathrm{NaOCl}$ aqueous solution for 120 s, followed by soaking in a 1000 ppm $\mathrm{NaHSO}_{3}$ aqueous solution for $30 \mathrm{~s}$, before a final wet curing step at $95{ }^{\circ} \mathrm{C}$ for $120 \mathrm{~s}$. The fabricated TFC membranes were rinsed thoroughly and stored in DI at $4{ }^{\circ} \mathrm{C}$. The PA fabrication protocol described above was used for all of the support membranes studied.

\subsection{Testing Systems and Protocols}

\subsubsection{Determination of Membrane Active Layer Transport Properties in RO Mode}

Intrinisc water permeability, $A, \mathrm{NaCl}$ permeability coefficient, $B$, and salt rejection, $R$, of the fabricated membranes were evaluated in a laboratory-scale crossflow RO test unit [24], 
following the procedure described in our previous publication [20]. The effective membrane area was $20.02 \mathrm{~cm}^{2}$, the crossflow velocity was fixed at $21.4 \mathrm{~cm} / \mathrm{s}$, and the temperature was constant at $25 \pm 0.5{ }^{\circ} \mathrm{C}$. The loaded membrane was first compacted with DI at an applied pressure, $\Delta P$, of 400 psi (27.6 bar) until the permeate flux reached a steady state (at least $15 \mathrm{~h}$ ). Pure water flux, $J_{\mathrm{w}}$, was calculated by dividing the volumetric permeate rate by the membrane area. Salt rejection was characterized by keeping the applied pressure at 400 psi (27.6 bar) and measuring rejection of $50 \mathrm{mM} \mathrm{NaCl}$ solution using a calibrated conductivity meter (Oakton Instruments, Vernon Hills, IL).

Intrinsic water permeability, $A$, was determined by dividing the water flux by the applied pressure, $A=J_{W} / \Delta P$. Observed $\mathrm{NaCl}$ rejection, $R$, was determined from the difference in bulk feed $\left(c_{b}\right)$ and permeate $\left(c_{\mathrm{p}}\right)$ salt concentrations, $R=1-c_{p} / c_{b}$. The rejection values for each sample are the average of three different measurements, each collected over approximately 30 min. The solute permeability coefficient, $B$, was determined from $[14,19]$ :

$$
B=J_{w}\left(\frac{1-R}{R}\right) \exp \left(-\frac{J_{w}}{k}\right)
$$

where $k$, the mass transfer coefficient for the crossflow cell, is calculated from correlation for a rectangular cell geometry and laminar flow [25].

2.4.2. Testing Membrane Performance in FO Mode and Determination of Membrane Support Structural Parameters

The experimental crossflow FO system employed is similar to that described in our previous studies [16, 20, 26, 27]. The unit was custom built with channel dimensions of $77 \mathrm{~mm}$ long, 26 $\mathrm{mm}$ wide, and $3 \mathrm{~mm}$ deep, giving an effective membrane area of $20.02 \mathrm{~cm}^{2}$ on both sides of the membrane. The unit was operated with co-current crossflow without mesh spacers. Variable speed gear pumps (Cole-Parmer, Vernon Hills, IL) were used to pump the solutions in closed loops at a crossflow velocity of $21.4 \mathrm{~cm} / \mathrm{s}$ and a water bath (Neslab, Newington, $\mathrm{NH}$ ) maintained the temperature of both the feed and draw solutions at $25 \pm 0.5^{\circ} \mathrm{C}$. All membranes were tested in FO mode, with the porous support layer against the draw solution and the active layer against the feed solution. 
The experimental protocol to determine water flux is similar to that previously described $[16,20,27]$. The volume of both the feed and draw solutions at the start of each experimental run was $2.0 \mathrm{~L}$. A $1.0 \mathrm{M} \mathrm{NaCl}$ solution was used for the draw solution and DI was used as the feed solution. The resulting bulk osmotic pressure difference, $\Delta \pi$, calculated using a software package from OLI Systems, Inc. (Morris Plains, NJ), was 702 psi (48.4 bar). After the water flux stabilized, the flux was taken as the average reading over $1 \mathrm{~h}$. The draw solution concentration is assumed to be constant throughout the experiment, since the volumetric water flux was low relative to the volume of draw solution.

The membrane support layer resistance to solute diffusion, $K$, was determined using [28]:

$$
K=\left(\frac{1}{J_{w}}\right) \ln \frac{B+A \pi_{D, b}}{B+J_{w}+A \pi_{F, m}}
$$

where $J_{\mathrm{w}}$ is the measured water flux, $\pi_{\mathrm{D}, \mathrm{b}}$ is the bulk osmotic pressure of the draw solution, and $\pi_{\mathrm{F}, \mathrm{m}}$ is the osmotic pressure at the membrane surface on the feed side ( 0 bar for DI feed). The resistance to diffusion $K$ can be expressed as the reciprocal of a thin-film mass transfer coefficient [29]:

$$
K=\frac{t_{s} \tau}{D \varepsilon}
$$

where $D$ is the diffusion coefficient of the draw solute, $t_{\mathrm{s}}$ is the support layer thickness, $\tau$ the tortuosity, and $\varepsilon$ the porosity [16].

We define the membrane structural parameter $S$ :

$$
S=K D=\frac{t_{s} \tau}{\varepsilon}
$$

which is independent of the draw solution properties, assuming the draw solutes do not swell or plasticize the PSf and PET layers. We can further separate the effect of the support layer thickness, $t_{\mathrm{s}}$, arriving at a new parameter depicting the ratio of porosity to tortuosity:

$$
\frac{\varepsilon}{\tau}=\frac{t_{s}}{S}
$$


This thickness-independent porosity parameter, which describes the structure of the membrane support layer, is bounded between 0 and 1 because the theoretical range of porosity is between 0 and 1 and tortuosity is greater than or equal to 1 .

\subsection{SEM Imaging and Size Measurement of Active Pores and Cross-sectional Macrovoids}

All micrographs were acquired using a Hitachi Ultra-High-Resolution Analytical Field Emission Scanning Electron Microscope (FE-SEM) SU-70. To obtain cross-sections, wet membrane samples were flash-frozen in liquid nitrogen and subsequently cracked. Both membrane surface and cross-section samples were dried overnight prior to sample mounting. An Emitech SC7620 sputtering machine was used to coat surface samples for $30 \mathrm{~s}$ and cross-section samples for $45 \mathrm{~s}$

with gold-platinum. ImageJ 1.41 software (National Institutes of Health, Bethesda, Maryland, USA) was used to determine the average pore and macrovoid diameter by taking 100 and 25 measurements, respectively. Average membrane thickness was measured at 5 different locations for each membrane sample using a Mitutoyo 293-330 digital micrometer (Mississauga, Ontario Canada).

\section{Results and Discussion}

In the following sections, a systematic analysis of the relationship between the observed support layer structure and processing conditions will be presented. Results from RO and FO experiments will then be used to relate the membrane performance to membrane structure. An understanding of how processing conditions affect membrane structure and consequently membrane performance provides a basis for the rational selection of the support layer formation conditions in order to enhance FO performance.

\subsection{Support Layer Structure}

\subsubsection{Role of solvent-polymer interaction}

The cloud point correlates directly with the position of the binodal boundary on a ternary phase diagram [19], allowing the thermodynamic properties of the system at the point of phase separation to be characterized. Therefore, the cloud point value, which can be determined by 
simple turbidity measurements [30], is useful for comparing the behavior of casting dope solutions with different solvent compositions. Although the system investigated in this study consists of four components (NMP/DMF/PSf/water), the thermodynamic state can be represented with a simplified pseudo-ternary phase diagram where NMP and DMF are grouped together for analysis as "solvent". Cloud point data for our system with varying DMF and NMP concentrations in the initial solvent mixture are presented in Figure 2. As more DMF is incorporated into the mixture, a smaller amount of water is needed to initiate phase separation (Figure 2A). On the pseudo-ternary diagram, this translates to a shift of the binodal closer to the polymer-solvent axis (Figure 2B) for higher DMF concentrations. This observation is in agreement with NMP being a better solvent for PSf than DMF [31].

Figure 2. Plot of (A) the observed cloud points of $12 \%$ PSf and (B) related binodal points in the ternary diagram as a function of DMF concentration in the dope solution. Cloud point is calculated as the amount of nonsolvent (DI water) added to the dope to turn it turbid, expressed in wt \% with respect to the polymer solution plus the nonsolvent.

For the PSf-solvent-water system, where strong polymer-nonsolvent repulsion is present, the value of the Flory-Huggins interaction parameter, $\chi_{\mathrm{PS} f} /$ water, determines the location of the point where the binodal intersects the polymer-nonsolvent axis [22]. A value of 5.9, a high positive value consistent with strong repulsive forces, was found for $\chi_{\mathrm{PSf} / \text { water }}$ using swelling experiments [32], thereby fixing the intersection in high polymer concentration region. This fixed intersect, together with the measured cloud point data, provides a reasonable estimate of the binodal boundary for the different systems.

In addition to the thermodynamic conditions during phase separation, polymer precipitation is affected by the rates of nonsolvent influx and solvent outflux to and from the polymer solution film, respectively. Therefore, the final membrane morphology depends on the balance between the solvent-nonsolvent inter-diffusion and the polymer vitrification, defined as the process in which the casting solution solidifies crossing the glassy region in the phase diagram [33]. NMP is a more favorable solvent for PSf [31] and, hence, permeates into the precipitation bath more slowly than DMF. A slower rate of outward solvent diffusion allows a more rapid influx of nonsolvent into the precipitating film. This difference in solvent-nonsolvent exchange rates between NMP and DMF results in rapid and slow advancing nonsolvent fronts, respectively. This front initiates a phase separation of the system as it advances into the polymer 
film [18]. Therefore, in a mixed solvent system, the velocity of the phase separation front can be tailored by controlling the relative amounts of the two solvents.

SEM micrographs of the membrane cross-sections are presented in Figure 3. The membranes were all cast from 12 wt \% PSf solutions with the concentration of DMF in the casting solution increasing from $0 \mathrm{wt} \%$ to $100 \mathrm{wt} \%$ in panels $2 \mathrm{~A}$ to $2 \mathrm{E}$, respectively. In all the investigated cases where NMP is present in the solvent mixture, the structure is dominated by macrovoids (Figure 3A-B-C-D). The finger-like pore structure starts just beneath the top surface and span the entire membrane thickness. This finding is consistent with the observation that macrovoids nucleate just beneath the free surface [34], then grow into the film when the inward flux of nonsolvent exceeds the outward flux of solvent [33]. When NMP is used in the solvent mixture, the nonsolvent diffusion front moves at a faster rate than the vitrification front, the system is under rapid demixing conditions, and the driving force to create extended macrovoids is sustained [33].

Figure 3. SEM micrographs displaying the cross-section of membranes cast at a fixed PSf concentration (12 wt \%) and increasing DMF concentrations: (A) 0, (B) 25, (C) 50, (D) 75, and (E) 100\%.

As the DMF content increases, the nonsolvent advances into the polymer solution film more slowly, while the vitrification front moves more quickly relative to the nonsolvent front, due to the shift of the binodal boundary, causing a transition to less rapid (delayed) onset of demixing. This transition is accompanied by a progressive decrease in the size of macrovoids and the formation of a denser and thicker skin layer [34], which will eventually create a cellular or sponge-like morphology free of macrovoids [22]. Using the SEM micrographs in Figure 3, the macrovoid sizes are quantitatively evaluated by measuring the average finger width (Table 1). Consistent with expectations, the average finger width decreases with increasing DMF content, and for $100 \mathrm{wt} \% \mathrm{DMF}$, the layer has a sponge-like morphology over the entire thickness (Figure 3E).

Table 1. Summary of active (top) side pore sizes and cross-sectional finger width of the support layers. Values are the average of 3 separately cast support layers. "NA" means Not Applicable, for the membranes showing a sponge-like structure with no observed fingers. Pore sizes for the cell related to 18 wt \% PSf in $100 \%$ DMF are not reported because a representative value could not be confidently measured. 
The final thickness of the support membranes is also influenced by the processing conditions used during the layer formation. The thicknesses, measured using a digital micrometer, monotonically decreases as the DMF concentration in the initial dope increases (Table 2), despite maintaining a constant gate height of $250 \mu \mathrm{m}$ ( 10 mils) during casting. Under less rapid demixing conditions, the PSf has more time to relax and begins to vitrify later in the phase inversion process, thereby resulting in a thinner film.

Table 2. Summary of TFC-FO thicknesses measured prior to RO testing. The percent compaction of the membrane after testing in RO mode at an applied pressure of 400 psi (27.6 bar) and $25 \pm 0.5^{\circ} \mathrm{C}$ is shown in the square brackets. Values are the average of 3 separately cast membranes.

In addition to the structure of the porous sublayer, the characteristics of the top layer are crucial for membrane functionality. The structure, porosity, and hydrophobicity of the skin layer were demonstrated to impact the permeability and separation properties of the PA barrier layer subsequently formed via interfacial polymerization [35, 36]. The average and standard deviation of surface pore diameters after the phase inversion process are reported in Table 1. The pore size decreases sharply for a layer cast from 25 wt \% DMF, compared to the 100\% NMP condition, and with further increases in DMF concentration, the pore size steadily increases.

It has been hypothesized that the denser skin layer and the more porous sublayer are formed by two separate mechanisms [23]. For the top skin layer, the structure is primarily determined by the order of events during phase separation [37]. Two scenarios are possible. In the first scenario, liquid-liquid phase separation occurs prior to the concentrated polymer phase beginning to gel. Here, the precipitation pathway intersects the binodal before crossing into the gelation region, causing a lower polymer concentration and an open skin layer with larger pores (Case I). For the second scenario, the polymer begins to gel before phase separation occurs (i.e. the precipitation pathway passes through the gelation boundary before entering into the twophase region). This results in a higher polymer concentration at the top surface and a denser skin layer with smaller pores (Case II). We hypothesize that at $0 \mathrm{wt} \%$ DMF the ratio of NMP outflux to water influx is small, giving rise to conditions for Case I. However, at 25 wt \% DMF, the ratio of solvent outflux to water influx increases altering the formation pathway to that of Case II. 
Therefore, the surface pore sizes of membranes cast in $25 \mathrm{wt} \%$ DMF are smaller than those made with only NMP. Then, with increasing DMF concentrations, the formation mechanism is Case I, but the average pore diameter changes due to shifting of the binodal boundary. As the binodal approaches the polymer-solvent axis, there will be a lower local concentration of PSf when the polymer vitrifies, resulting in larger surface pores [17].

Figure 4 presents SEM micrographs of the bottom surface of membranes with the PET fabric carefully removed. The membranes presented were cast using 100\% NMP, a 50:50 mixture of NMP and DMF, and 100\% DMF as solvents. For the membranes where finger-like macrovoids were present, open pores on the bottom surface of the PSf support layer were observed (Figure 4A-B). This suggests that the macrovoids span the entire thickness of the PSf layer. The size of the bottom pores correlates well with the size of the macrovoids shown in Figure 3 and reported in Table 1. As the average width of the macrovoids decreases, the size of the pores at the bottom of the layer also decreases. For the membrane cast using $100 \mathrm{wt} \% \mathrm{DMF}$ solvent (Figure 4C), no large pores were seen. This result is expected because of the sponge-like morphology spanning the membrane thickness.

Figure 4. SEM micrographs displaying the bottom surface membranes cast at a fixed PSf concentration (12 wt \%) and increasing DMF concentrations: (A) 0, (B) 50, and (C) 100\%. For all samples, the PET non-woven fabric was carefully removed prior to imaging.

\subsubsection{Role of polymer concentration}

Representative cross-sectional SEM micrographs of membranes cast from solutions of varying PSf concentration are shown in Figure 5. The micrographs in the left column are of membranes that were cast from $100 \mathrm{wt} \%$ NMP solutions, and those in the right column were cast from 100 wt \% DMF solutions. Moving down the columns, the PSf concentrations are 9, 15, and $18 \mathrm{wt} \%$, respectively; membranes cast using 12 wt \% PSf were shown earlier in Figure 3. In general, increasing the polymer concentration in solution results in a higher viscosity, which tends to reduce transport rates thereby, producing slower demixing [34]. Additionally, when casting membranes from solutions with higher polymer concentrations, the precipitation paths cross the binodal at higher polymer concentrations [18, 34]. These factors combine to produce membranes with thicker top layers, lower porosities, and diminished macrovoid formation [22]. 
Figure 5. SEM micrographs displaying the cross-section of support membranes cast from (A, D) 9, (B, E) 15, and (C, F) 18 wt \% PSf concentration in 100\% NMP or DMF solvent. The micrographs in the left column were cast from $100 \%$ NMP, whereas the right column of micrographs relates to membranes cast from $100 \%$ DMF.

Our experimental observations were consistent with these trends. The membranes cast from $100 \mathrm{wt} \%$ NMP solutions (Figure 3A and Figure 5A-B-C) seem to have thicker skin layers as the PSf concentration increases. SEM micrographs show that the macrovoid size and length decreased with increasing polymer concentration; the finger diameter measurements presented in Table 1 confirm this observation. For the membranes cast from 100\% DMF solutions, a dense sponge-like morphology formed for PSf concentrations of $12 \mathrm{wt} \%$ and higher (Figures 3E and 5E-F).

The membrane formed from a 9 wt \% PSf in 100\% DMF solution (Figure 5D) had uniform finger-like macrovoids spanning the layer thickness, but with a relatively thick skin layer of a dense sponge-like morphology. This substantiates the claim that there are different structure formation pathways for the skin layer and the underlying sublayer. For the skin layer of the $100 \mathrm{wt} \%$ DMF membrane, vitrification began prior to phase separation, resulting in the formation of a dense skin. If the polymer is viscous enough to maintain slow demixing conditions, a sponge-like morphology persists. However, for the 9wt \% PSf solution, slow demixing conditions cannot be sustained because of the low solution viscosity, thereby resulting in the formation of macrovoids in the sublayer [34].

The observed trend of the membrane thickness fabricated at various polymer concentrations can be related to the structure formation mechanism (Table 2). The films cast from 100 wt \% NMP solutions all had similar thicknesses, with a small decrease at the highest PSf concentration. This is consistent with rapid demixing conditions where the polymer chains have little time to rearrange prior to commencement of vitrification. The membranes cast from 100 wt \% DMF solutions were thinner because the polymer was given time to rearrange due to the slow demixing conditions [23]. However, due to the transition in demixing regime that caused the change in membrane structure, the $9 \mathrm{wt} \%$ PSf membrane did not follow this trend.

Increasing the PSf concentration in the casting solution increases the local concentration of polymer at the film-bath interface when precipitation occurs (tending to produce Case II 
conditions for the top layer formation, as discussed earlier), which leads to surface pores with smaller radii. The measured average surface pore diameters follow this trend, regardless of the solvent employed (Table 1). A decrease in pore size with an increase in PSf concentration was also observed on the bottom side of the support layer (images not displayed). The presence of macrovoids in the sublayer is associated with open pores at the bottom surface, and a smaller finger width corresponds to smaller pores. In the case of sponge-like structures, no large open pores are observed at the bottom surface.

\subsubsection{Role of substrate layer wetting}

To investigate the role of the casting substrate on membrane structure, support layers were cast without the pretreatment step of wetting the PET layer with solvent. The compositions of the casting solutions used to form these support layers are 12 and 15 wt \% PSf in 100\% NMP solvent. Representative SEM micrographs of the cross-section and the bottom surface for membranes cast onto nonwetted PET that was secured to an underlying glass plate are shown in Figure 6. When the support layer was cast without pre-wetting the PET, the cross-sectional morphology was similar to that achieved by casting onto a wetted fabric, i.e. finger-like voids spanning the layer thickness were observed. However, the bottom side pore structure was

markedly different. The cross-section suggests that the polymer solution had seeped through the PET layer during casting, thus creating an additional PSf layer underneath the PET fabric (Figure 6B) that had a dense sponge-like morphology. Also, instead of the open pores (Figure 4), a closed bottom surface is present for support layer casting without pre-wetting the PET (Figure 6A). The solvent wetting the PET excludes the casting solution from the voids in the PET fabric, thus preventing it from contacting the underlying substrate [38]. Additionally, the presence of solvent in the fabric dilutes the casting solution at the fabric-film interface, thereby decreasing the local polymer concentration.

Figure 6. SEM micrographs displaying the (A) bottom and (B) cross-section of membranes cast onto non-wetted PET fabric fabricated from 15 wt \% PSf in 100\% NMP solvent. The PET fabric was not removed for the imaging of (A) or (B). 


\subsubsection{Influence of initial casting blade height on film structure}

Thicker support membranes were cast from 12 wt \% PSf in $100 \mathrm{wt} \%$ NMP by setting the gate height of the casting knife at $500 \mu \mathrm{m}$ ( 20 mils) instead of $250 \mu \mathrm{m}$ ( 10 mils). A cross-sectional micrograph of the resulting support layer structure is shown in Figure 7. Macrovoids did form in the upper portion (i.e., the section near the active layer) of the support membrane, but these transitioned to the denser sponge-like morphology in the lower portion of the membrane. This change in structure is attributed to the different rates of demixing that occur as phase precipitation proceeds. Initially, rapid demixing causes a finger-like morphology with macrovoids forming in the upper portion of the membrane. As the upper layer forms, it increases the resistance to the inward diffusion of nonsolvent, causing a transition to delayed (slow) demixing further into the film. Because delayed demixing favors the formation of a cellular sponge-like morphology, the transition to this type of structure was observed in the lower portion of the layer. This structure was not observed for the films cast the lower blade height because the total film thickness was not large enough to cause a transition from rapid to delayed demixing.

Figure 7. SEM micrograph displaying the cross-section of a support membrane cast from $12 \mathrm{wt} \%$ PSf in $100 \%$ NMP solvent that was cast at a blade height of 20 mils yielding a $266 \pm 12 \mu \mathrm{m}$ thick membrane. Note: 1 mil is equivalent to 0.001 inch or $25.4 \mu \mathrm{m}$.

\subsection{Membrane Performance}

\subsubsection{FO performance and membrane support layer porosity}

The experimentally measured FO water fluxes for the different TFC membranes are presented in Figure 8 and summarized in Table 3. To isolate the effects of support layer structure on FO water flux, the same PA formation protocol was used in the fabrication of all the membranes and only the support layer formulations were varied. For support membranes cast from 100\% NMP and DMF solutions with varying PSf concentration, the water flux increases as the polymer concentration decreases (Figure 8A). At concentrations of 9 and $12 \mathrm{wt} \%$, the average water fluxes for the membranes cast from the DMF solutions were higher than corresponding membranes cast from NMP solutions. The opposite result is observed for the 15 wt \% PSf membranes. Data for membranes cast at a constant PSf concentration of $12 \mathrm{wt} \%$ with varying 
solvent compositions are shown in Figure 8B. The water flux decreases as the DMF content increases from $0 \mathrm{wt} \%$ to $25 \mathrm{wt} \%$, while further increases in the DMF content resulted in the FO water flux also increasing. All FO water flux data are compared in Figure 8C. In this bubble plot, the bubble diameter corresponds to the magnitude of the water flux.

Table 3. Summary of Measured FO Water Flux $J_{w}$, NaCl Observed Rejection $R$, and Calculated Structural Parameter $S$, Porosity Parameter $\varepsilon / \tau$, Intrinsic permeability $A$, and $\mathrm{NaCl}$ Permeability Coefficient $B$ for the Membranes Tested ${ }^{\mathrm{a}, \mathrm{b}}$.

Figure 8. Comparison of FO water fluxes between the different TFC FO membranes cast in this study. (A) Water flux for membranes cast with varying PSf concentration in either all DMF or all NMP solvent. (B) Water flux for membranes cast at fixed PSf concentration (12 wt \%) and varying the NMP and DMF solvent mixture. (C) Bubble graph summarizing the data, where the size of each bubble is proportional to the FO flux value for each related membrane in the matrix. Data points are the average of 3 separately cast membranes, with error bars representing standard deviations. A line connecting data points is drawn only to guide the eye. Experimental conditions for FO flux were as follows: $1 \mathrm{M} \mathrm{NaCl}$ draw solution, DI feed solution, and feed and draw solution temperature of $25{ }^{\circ} \mathrm{C}$. A value for membranes cast at 18 wt \% PSf in $100 \%$ DMF is not included because the results were not reproducible enough to be considered statistically significant; however, the average FO flux of two separately cast membranes was $1.9 \mathrm{~L} \mathrm{~m}^{-2} \mathrm{~h}^{-1}$ $\left(1.1\right.$ gal ft $\left.^{-2} \mathrm{~d}^{-1}\right)$.

Due to the different amount of vertical shrinkage that can occur during the phase separation process, when examining the influence of membrane structure on FO water flux for different membranes, comparing the measured water fluxes or the membrane structural parameters is slightly misleading. The ratio of the membrane support layer porosity to tortuosity, $\varepsilon / \tau$, is a better indicator of the inherent resistance to diffusion provided by the structure. It describes the structure of the support layer after correcting for the effect of the membrane thickness. The value of the parameter can range from 0 to 1 , with a value of 1 being desired to minimize the detrimental effects of ICP. Experimentally, $\varepsilon / \tau$ was calculated by dividing the thickness of the membrane measured after FO testing (summarized in Table 2) by the membrane structural parameter, $S$, as determined from FO test. In this calculation, the contribution of the ultrathin selective layer to the total membrane thickness is considered negligible.

Figure 9 presents the membrane porosities in a manner identical to how Figure 8 presents the FO water fluxes. For casting solutions containing 100\% NMP or DMF, $\varepsilon / \tau$ increased as the 
PSf concentration decreased (Figure 9A). The changes in $\varepsilon / \tau$ were more dramatic for $100 \%$ DMF than 100\% NMP, as indicated by the greater slope of the trend line. Of all the membranes cast, the highest value of $\varepsilon / \tau$ was achieved using a PSf concentration of 9 wt $\%$ and DMF as a solvent.

Figure 9. Comparison of calculated porosity parameter $\varepsilon / \tau$ between the different TFC FO membranes cast in this study. (A) Porosity data for membranes cast varying PSf concentration in either all DMF or all NMP solvent. (B) Porosity data for membranes cast at fixed PSf concentration (12 wt \%) and varying the NMP and DMF solvent mixture. (C) Bubble graph summarizing the data, where the size of each bubble is proportional to the porosity parameter value for each related membrane in the matrix. Data points are the average of 3 separately cast membranes, with error bars representing standard deviations. A line connecting data points is drawn only to guide the eye. The porosity parameter is calculated using Eq. (5) and isolating the effect of membrane thickness. A value for membranes cast at $18 \mathrm{wt} \%$ PSf in $100 \%$ DMF is not included because the results were not reproducible enough to be considered statistically significant: however, the average calculated porosity parameter of two separately cast membranes was 0.012 .

Figure 9B displays $\varepsilon / \tau$ for membranes cast from solutions containing 12 wt $\%$ PSf with varying solvent compositions. It is interesting to note that after accounting for the effect of membrane thickness on water flux performance, the value of $\varepsilon / \tau$ decreases as the amount of DMF increases even though the water flux increased over most of this range. This begins to highlight the importance of both the support layer structure and the active layer properties in determining membrane performance, a topic that will be discussed in more detail in subsequent sections. The bubble graph plot of Figure 9C provides a visual summary of the $\varepsilon / \tau$ values for the membrane matrix evaluated in this study.

\subsection{2. $R O$ performance and membrane active layer parameters}

Permeate water flux and $\mathrm{NaCl}$ rejection, $R$, of all the cast membranes were measured in an $\mathrm{RO}$ cross-flow cell. The tests were carried out under conditions typical of brackish water desalination, with an applied pressure of $400 \mathrm{psi}$ (27.6 bar) and a feed $\mathrm{NaCl}$ concentration of 50 $\mathrm{mM}$. This allowed the calculation of the polyamide thin film parameters: $A$, the intrinsic water permeability, and $B$, the intrinsic $\mathrm{NaCl}$ permeability coefficient. Values of $A$ and $R$ are reported in Table 3 and Figure 10.

All membranes showed $\mathrm{NaCl}$ rejection values in excess of $95.5 \%$. The variability in selectivity within membranes cast from a single support layer recipe is ascribed to defects during 
hand-casting of the PA layers, and is likely to be minimized on a manufacturing line. However, some differences and trends between membranes cast from different recipes were noticed. These variations in selectivity are attributed to the ability to form a functional PA active layer on support skin layers with different surface porosities and pore sizes. In general, $\mathrm{NaCl}$ rejection increased as PSf concentration increased in the support layer casting solution, for both NMP and DMF solvents. This finding may suggest that when a thicker skin layer and smaller surface pores are present on the support layer, an integral PA layer can be fabricated more easily. This trend with support surface pore size is expected [39]. However, other support properties might impact PA formation, such as pore size distribution and number density, and the presence of defects. Salt rejection also increased as DMF concentration increased in the PSf casting solution. Additionally, it was observed that salt rejection was higher for membranes cast using DMF solvent (Figure 10A-B) compared to membranes cast from NMP. This observation confirms that a thicker sponge-like stratum at the top of the support layer helps to minimize PA defects and to obtain an active layer with superior transport characteristics [14, 20].

Overall, the opposite trends were found for the active layer intrinsic water permeability. At increased support skin layer thickness and decreased size of support surface pores, interfacial polymerization gives rise to a PA layer with lower observed permeability [39]. In general, the sponge-like morphology proves to be a pore structure more apt for the fabrication of a PA layer with better transport characteristics [14]. This is evident when inspecting Figure 11, presenting the figure of merit for the different TFC FO membranes cast in this study. The figure of merit is defined as $A^{2} / B$, where $A$ is the intrinsic water permeability coefficient and $B$ is the solute permeability coefficient [40]. Membranes with a sponge-like morphology or with a thicker sponge skin at the top of the support layer are more favorable for the formation of an active film with superior transport properties, and have larger $A^{2} / B$ parameters. As we discuss later, a larger figure of merit translates into an improved membrane FO performance.

Figure 10. Comparison of observed $\mathrm{NaCl}$ rejection between the different TFC FO membranes cast in this study, measure in RO. (A) Salt rejection for membranes cast by varying PSf concentration in either all DMF or all NMP solvent. (B) Salt rejection for membranes cast at fixed PSf concentration (12 wt \%) and varying the NMP and DMF solvent mixture. (C) Bubble graph summarizing the data, where the size of each bubble is proportional to the $1 /(1-R)$ value, or inverse of the salt passage, for each related membrane in the matrix. Data points are the average of 3 separately cast membranes, with error bars representing standard deviations. A line connecting data points is drawn only to guide the eye. Conditions for rejection experiments were as follows: $50 \mathrm{mM} \mathrm{NaCl}$ feed solution, 400 psi (27.6 bar) 
applied pressure, cross-flow of $21.4 \mathrm{~cm} / \mathrm{s}$, and temperature of $25{ }^{\circ} \mathrm{C}$. A value for membranes cast at 18 wt \% PSf in $100 \%$ DMF is not included because the results were not reproducible enough to be considered statistically significant: however, the average observed $\mathrm{NaCl}$ rejection of two separately cast membranes was $96.2 \%$.

Figure 11. Bubble graph of $A^{2} / B$ for the different TFC FO membranes cast in this study, as measured from RO experiments, with $A$ being the pure water intrinsic permeability and $B$ the salt permeability coefficient. Data points are the average of 3 separately cast membranes. RO experimental conditions were as follows: $50 \mathrm{mM} \mathrm{NaCl}$ feed solution, 400 psi (27.6 bar) applied pressure, cross-flow of $21.4 \mathrm{~cm} / \mathrm{s}$, and temperature of $25{ }^{\circ} \mathrm{C}$. A value for membranes cast at $18 \mathrm{wt} \%$ PSf in $100 \%$ DMF is not included because the results were not reproducible enough to be considered statistically significant.

\subsubsection{Performance of membranes fabricated without substrate pre-treatment}

Membranes without open pores on the support layer bottom surface (i.e., those cast without a pre-wetting step) showed markedly reduced water flux performance in FO tests. Membranes cast from 12 wt \% PSf in 100\% NMP solvent produced a water flux of $5.4 \pm 0.6 \mathrm{~L} \mathrm{~m}^{-2} \mathrm{~h}^{-1}$ (Table 3), which was considerably lower than the water flux of membranes made with an identical formulation but with the fabric pre-treatment step $\left(13.9 \pm 1.0 \mathrm{~L} \mathrm{~m}^{-2} \mathrm{~h}^{-1}\right)$. These results translate into a significantly lower value of $\varepsilon / \tau$ for the membrane support layer (reduced from $0.201 \pm$ 0.020 to $0.040 \pm 0.008$ ). Similar results were observed for membranes cast from $15 \mathrm{wt} \%$ PSf in 100\% NMP. FO water flux was diminished drastically from $9.2 \pm 0.2 \mathrm{~L} \mathrm{~m}^{-2} \mathrm{~h}^{-1}$ to below the detection limit of the measuring system. This result demonstrates the need to produce an open bottom surface by preventing the formation of a dense PSf wetting layer, i.e. the enrichment of PSf at the polymer solution-substrate interface that blocks the pores of the support layer.

\subsubsection{Performance of membranes fabricated at higher initial polymer film thickness}

Membranes with finger-like macrovoids that do not span the entire support layer thickness exhibited lower a FO water flux $\left(5.6 \mathrm{~L} \mathrm{~m}^{-2} \mathrm{~h}^{-1}\right)$ than membranes where the macrovoids extend to

the layer bottom $\left(13.9 \pm 1.0 \mathrm{~L} \mathrm{~m}^{-2} \mathrm{~h}^{-1}\right)$. However, a higher initial polymer film thickness would result in a thicker support layer which, in turn, causes more severe ICP effect, thereby reducing membrane performance. A less biased approach is to decouple the effects of support layer thickness by comparing their $\varepsilon / \tau$ values. When the macrovoids do not span the support layer, $\varepsilon / \tau$ 
was determined to be 0.057 , almost a $70 \%$ decrease relative to the membranes with macrovoids spanning the support thickness, which have a $\varepsilon / \tau$ value of $0.201 \pm 0.022$.

\subsection{Relating membrane structure to FO performance}

The first section of this paper discussed the structure formation of TFC support layers fabricated under a variety of fabrication conditions. The second part presented the performance of the resulting TFC membranes in FO and RO operation. This section examines the FO membrane performance results in light of the observed support layer structure. By drawing a connection between the observed structure of a membrane and its performance, we gain a better understanding of the phenomena controlling water flux in FO operations. This enhanced understanding can help to guide further efforts to tailor the support layer structure for better performance.

\subsubsection{The ideal support layer maximizes $\varepsilon / \tau$}

ICP, which occurs because the support layer of the membrane acts as an unstirred boundary layer, causes the observed water flux in FO operation to be lower than that predicted from bulk osmotic pressure difference. Therefore, increasing $\varepsilon / \tau$ (i.e., decreasing the effective

thickness of the boundary layer, $S$ ) should improve FO performance. For membranes cast from a single solvent (100\% NMP or DMF), $\varepsilon / \tau$ decreases with increasing PSf wt \%. In particular, for NMP solvent this trend corresponds to a decrease in finger-like structure width as seen in the cross-sectional micrographs (Figures $3 \mathrm{~A}$ and 5A-B-C) and the data presented in Table 1. These changes in $\varepsilon / \tau$ correlate directly with changes in measured water fluxes. Lowering polymer concentration in the casting solution is one way to increase the porosity and hence to reduce ICP.

\subsubsection{A finger-like morphology maximizes $\varepsilon / \tau$}

At an equivalent PSf concentration in the casting solution, membranes with finger-like morphology have a higher $\varepsilon / \tau$ than the corresponding membranes with a sponge-like morphology. For 12 wt\% PSf, an increase in DMF content in the casting solution translates into smaller finger-like features that correlate with a steady decrease in $\varepsilon / \tau$ (Figures 3 and 9 ). Also, when using $100 \%$ DMF as a solvent and lowering the polymer concentration, the dramatic increase in $\varepsilon / \tau$ achieved by using a 9 wt \% PSf solution is explained by the transition from a sponge-like to a 
finger-like morphology (Figure 5D). These observations confirm that a finger-like morphology with large macrovoids is favorable for reduction of ICP in FO operations.

\subsubsection{Macrovoids extending to the bottom surface maximize $\varepsilon / \tau$}

The structure-performance relationship of membranes with a dense PSf wetting layer [38, 41] or with truncated macrovoids suggests that driving the formation of the macrovoids to the bottom surface is necessary for producing high performance membranes. Despite macrovoids spanning most of the support layer thickness when substrate layer was not wetted during fabrication (Figure 6), these membranes have significantly lower calculated values of $\varepsilon / \tau$ and water fluxes than those obtained from similar formulations but possessing continuous macrovoids (Figure 4A). This difference is due to the dense layer at the bottom surface, which contributes an additional resistance to mass transfer, thus increasing ICP and reducing water flux. In order to maximize performance in FO, an open bottom layer with a high porosity is necessary.

\subsubsection{The ideal support layer structure facilitates a high performance active layer}

Further examination of the results for membranes cast from different solvent mixtures and 12 wt \% PSf, demonstrates that driving the formation of macrovoids and reducing ICP is not the only consideration when fabricating the PSf support layer. As the ratio of DMF to NMP in the casting solution increases, the inhibition of macrovoid formation correlates to a lower $\varepsilon / \tau$. However, the trend of FO water fluxes for these membranes does not correlate directly with the support layer porosity. For instance, while $\varepsilon / \tau$ decreased as DMF content increased (Figure 9B), the corresponding water fluxes increased over the same range (Figure 8B). In another example, $\varepsilon / \tau$ decreased more sharply with increasing PSf concentration for DMF solvent in comparison to NMP solvent (Figure 9A). However, the same trend was not observed for the FO water flux, with the DMF membranes showing a more gradual decline in water flux (Figure 8A). These results imply that the adverse effects of ICP on FO water flux can be offset, and at times overcome, by the positive effect achieved by fabricating a PA layer with superior transport properties (i.e., high $A$ and low $B$ values). Therefore, having a large $A^{2} / B$ parameter [40] is as important to FO performance as obtaining a low structural parameter $S$, and can be accomplished by achieving a favorable morphology in the top skin portion of the support layer. Further attempts to modify the support layer structure in order to fabricate a high performance FO membrane need to optimize both the bulk and skin layer structures. 


\section{Concluding Remarks}

In this work, we focused on elucidating the design requirements for the support layer of TFC membranes specifically tailored for FO operation. This goal was pursued by systematically varying the casting conditions of the PSf support layer. The resulting array of support layer structures was correlated to TFC membrane performance. For enhanced performance, FO membranes should be engineered to minimize the effects of ICP while maintaining high water permeability and low salt passage. The observed flux behavior of our hand-cast FO membranes highlights an intricate interrelationships between $A, B$, and $S$. Conditions favoring a high porosity for reducing ICP often compromise the formation of an active layer with the required properties [36]. The ideal support layer fabrication would allow the structural dependence of the bulk and skin layer to be controlled independently during support membrane fabrication. In doing so, the membrane properties, $A, B$, and $S$, could be tailored unconstrained of each other.

Varying the polymer concentration in the casting solution and the relative amount of different solvents produced different support structures. Other approaches might involve, for instance, the use of additives in the casting solution, varying the temperature of the precipitation bath, or including an evaporation step before the nonsolvent induced precipitation. With this being said, optimized $S, A$, and $B$ values need to be incorporated into FO membranes whose chemical stability and mechanical integrity also match the requirements for the specific osmotically-driven membrane process of interest. In time, an array of membranes will aid in advancing osmotically-driven membrane processes such as wastewater and industrial water reclamation and reuse, seawater and brackish water desalination, and pressure retarded osmosis.

\section{Acknowledgments}

This publication is based on work supported in part by Award No. KUS-C1-018-02, made by King Abdullah University of Science and Technology (KAUST); the WaterCAMPWS, a Science and Technology Center of Advanced Materials for the Purification of Water with Systems under the National Science Foundation Grant CTS-0120978; and Oasys Water Inc. We also acknowledge the NWRI-AMTA Fellowship for membrane technology (to Alberto Tiraferri) and a Graduate Fellowship (to Ngai Yin Yip) made by the Environment and Water Industrial Development Council of Singapore. 


\section{References}

[1] R.L. McGinnis, M. Elimelech, Global Challenges in Energy and Water Supply: The Promise of Engineered Osmosis, Environmental Science \& Technology, 42 (2008) 8625-8629.

[2] B. Mi, M. Elimelech, Organic Fouling of Forward Osmosis Membranes: Fouling Reversibility and Cleaning without Chemical Reagents, Journal of Membrane Science, 348 (2010) 337-345.

[3] T.Y. Cath, A.E. Childress, M. Elimelech, Forward osmosis: Principles, applications, and recent developments, Journal of Membrane Science, 281 (2006) 70-87.

[4] R.E. Kravath, J.A. Davis, Desalination of Sea-Water by Direct Osmosis, Desalination, 16 (1975) 151-155.

[5] J.L. Cartinella, T.Y. Cath, M.T. Flynn, G.C. Miller, K.W. Hunter, A.E. Childress, Removal of natural steroid hormones from wastewater using membrane contactor processes, Environmental Science \& Technology, 40 (2006) 7381-7386.

[6] T.Y. Cath, D. Adams, A.E. Childress, Membrane contactor processes for wastewater reclamation in space II. Combined direct osmosis, osmotic distillation, and membrane distillation for treatment of metabolic wastewater, Journal of Membrane Science, 257 (2005) 111-119.

[7] T.Y. Cath, S. Gormly, E.G. Beaudry, M.T. Flynn, V.D. Adams, A.E. Childress, Membrane contactor processes for wastewater reclamation in space Part I. Direct osmotic concentration as pretreatment for reverse osmosis, Journal of Membrane Science, 257 (2005) 85-98.

[8] R.W. Holloway, A.E. Childress, K.E. Dennett, T.Y. Cath, Forward osmosis for concentration of anaerobic digester centrate, Water Research, 41 (2007) 4005-4014.

[9] W. Tang, H.Y. Ng, Concentration of brine by forward osmosis: Performance and influence of membrane structure, Desalination, 224 (2008) 143-153.

[10] A. Achilli, T.Y. Cath, E.A. Marchand, A.E. Childress, The forward osmosis membrane bioreactor: A low fouling alternative to MBR processes, Desalination, 239 (2009) 10-21.

[11] E.M. Garcia-Castello, J.R. McCutcheon, M. Elimelech, Performance evaluation of sucrose concentration using forward osmosis, Journal of Membrane Science, 338 (2009) 61-66.

[12] B. Jiao, A. Cassano, E. Drioli, Recent advances on membrane processes for the concentration of fruit juices: a review, Journal of Food Engineering, 63 (2004) 303-324.

[13] Q. Yang, K.Y. Wang, T.-S. Chung, A novel dual-layer forward osmosis membrane for protein enrichment and concentration, Separation and Purification Technology, 69 (2009) 269274.

[14] R. Baker, Membrane technology and applications, 2nd ed., Wiley, 2004.

[15] K.D. Vos, F.O. Burris, R.L. Riley, Kinetic Study of Hydrolysis of Cellulose Acetate in $\mathrm{Ph}$ Range of 2-10, Journal of Applied Polymer Science, 10 (1966) 825-832.

[16] J.R. McCutcheon, M. Elimelech, Influence of concentrative and dilutive internal concentration polarization on flux behavior in forward osmosis, J. Membr. Sci., 284 (2006) 237247.

[17] G.E. Gaides, A.J. Mchugh, Measurement and Analysis of Bath-Side Interfacial Concentration Gradients during Phase Inversion, J. Membr. Sci., 74 (1992) 83-94.

[18] A.J. Mchugh, C.S. Tsay, Dynamics of the Phase Inversion Process, Journal of Applied Polymer Science, 46 (1992) 2011-2021.

[19] J. Mulder, Basic principles of membrane technology, 2nd ed., Springer, 1996. 
[20] N.Y. Yip, A. Tiraferri, W.A. Phillip, J.D. Schiffman, M. Elimelech, High Performance Thin-Film Composite Forward Osmosis Membrane, Environ. Sci. Technol., 44 (2010) 38123818.

[21] R. Wang, L. Shi, C.Y.Y. Tang, S.R. Chou, C. Qiu, A.G. Fane, Characterization of novel forward osmosis hollow fiber membranes, J. Membr. Sci., 355 (2010) 158-167.

[22] P. vandeWitte, P.J. Dijkstra, J.W.A. vandenBerg, J. Feijen, Phase separation processes in polymer solutions in relation to membrane formation, J. Membr. Sci., 117 (1996) 1-31.

[23] J.G. Wijmans, J. Kant, M.H.V. Mulder, C.A. Smolders, Phase-Separation Phenomena in Solutions of Polysulfone in Mixtures of a Solvent and a Nonsolvent - Relationship with Membrane Formation, Polymer, 26 (1985) 1539-1545.

[24] W.S. Ang, M. Elimelech, Protein (BSA) fouling of reverse osmosis membranes: Implications for wastewater reclamation, J. Membr. Sci., 296 (2007) 83-92.

[25] E.M.V. Hoek, A.S. Kim, M. Elimelech, Influence of crossflow membrane filter geometry and shear rate on colloidal fouling in reverse osmosis and nanofiltration separations, Environmental Engineering Science, 19 (2002) 357-372.

[26] J.R. McCutcheon, M. Elimelech, Influence of membrane support layer hydrophobicity on water flux in osmotically driven membrane processes, J. Membr. Sci., 318 (2008) 458-466.

[27] J.R. McCutcheon, R.L. McGinnis, M. Elimelech, A novel ammonia-carbon dioxide forward (direct) osmosis desalination process, Desalination, 174 (2005) 1-11.

[28] S. Loeb, L. Titelman, E. Korngold, J. Freiman, Effect of porous support fabric on osmosis through a Loeb-Sourirajan type asymmetric membrane, J. Membr. Sci., 129 (1997) 243-249.

[29] K.L. Lee, R.W. Baker, H.K. Lonsdale, Membranes for Power-Generation by PressureRetarded Osmosis, J. Membr. Sci., 8 (1981) 141-171.

[30] W. Albrecht, T. Weigel, M. Schossig-Tiedemann, K. Kneifel, K.N. Peinemann, D. Paul, Formation of hollow fiber membranes from poly(ether imide) at wet phase inversion using binary mixtures of solvents for the preparation of the dope, J. Membr. Sci., 192 (2001) 217-230.

[31] C. Hansen, Hansen Solubility Parameters: A user's handbook, CRC Press, Boca Raton, Fla, 2007.

[32] D.M. Koenhen, M.H.V. Mulder, C.A. Smolders, Phase separation phenomena during formation of asymmetric membranes, Journal of Applied Polymer Science, 21 (1977) 199-215.

[33] S.A. McKelvey, W.J. Koros, Phase separation, vitrification, and the manifestation of macrovoids in polymeric asymmetric membranes, J. Membr. Sci., 112 (1996) 29-39.

[34] C.A. Smolders, A.J. Reuvers, R.M. Boom, I.M. Wienk, Microstructures in Phase-Inversion Membranes .1. Formation of Macrovoids, J. Membr. Sci., 73 (1992) 259-275.

[35] A.K. Ghosh, E.M.V. Hoek, Impacts of support membrane structure and chemistry on polyamide-polysulfone interfacial composite membranes, J. Membr. Sci., 336 (2009) 140-148.

[36] H.K. Lonsdale, R.L. Riley, C.R. Lyons, D.P. Carosella, Transport in Composite Reverse Osmosis Membranes, in: M. Bier (Ed.) Membrane Processes in Industry and Biomedicine, Plenum Press, New York, 1971, pp. 101-122.

[37] M.H.V. Mulder, J.O. Hendrikman, J.G. Wijmans, C.A. Smolders, A rationale for the preparation of asymmetric pervaporation membranes, Journal of Applied Polymer Science, 30 (1985) 2805-2820.

[38] P. Aerts, I. Genne, R. Leysen, P.A. Jacobs, I.F.J. Vankelecom, The role of the nature of the casting substrate on the properties of membranes prepared via immersion precipitation, J. Membr. Sci., 283 (2006) 320-327. 
[39] P.S. Singh, S.V. Joshi, J.J. Trivedi, C.V. Devmurari, A.P. Rao, P.K. Ghosh, Probing the structural variations of thin film composite RO membranes obtained by coating polyamide over polysulfone membranes of different pore dimensions, J. Membr. Sci., 278 (2006) 19-25.

[40] H.K. Lonsdale, Recent Advances in Reverse-Osmosis Membranes, Desalination, 13 (1973) 317-332.

[41] S. Zhang, K.Y. Wang, T.-S. Chung, H. Chen, Y.C. Jean, G. Amy, Well-constructed cellulose acetate membranes for forward osmosis: Minimized internal concentration polarization with an ultra-thin selective layer, J. Membr. Sci., 360 522-535. 


\section{Table and Figures}

Table 1. Summary of active (top) side pore sizes and cross-sectional finger width of the support layers. Values are the average of 3 separately cast support layers. "NA" means Not Applicable, for the membranes showing a sponge-like structure with no observed fingers. Pore sizes for the cell related to $18 \mathrm{wt} \%$ PSf in 100\% DMF are not reported because a representative value could not be confidently measured.

\begin{tabular}{|c|c|c|c|c|c|c|}
\hline & \multicolumn{5}{|c|}{$\begin{array}{c}\text { Support Layer Pore Size }(\mathrm{nm}) \\
\text { [Support Layer Finger Width }(\mu \mathrm{m})]\end{array}$} \\
\hline & & \multicolumn{5}{|c|}{ DMF Concentration (wt \%) $\longrightarrow$} \\
\hline & & 0 & 25 & 50 & 75 & 100 \\
\hline $\begin{array}{l}\widehat{\circ} \\
\text { त् } \\
\underline{3}\end{array}$ & 9 & $\begin{array}{c}38.8 \pm 18.4 \mathrm{~nm} \\
{[27.3 \pm 6.3 \mu \mathrm{m}]}\end{array}$ & & & & $\begin{array}{l}39.6 \pm 15.6 \mathrm{~nm} \\
{[9.9 \pm 1.6 \mu \mathrm{m}]}\end{array}$ \\
\hline 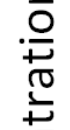 & 12 & $\begin{array}{c}38.5 \pm 14.1 \mathrm{~nm} \\
{[20.0 \pm 6.2 \mu \mathrm{m}]}\end{array}$ & $\begin{array}{c}22.1 \pm 9.1 \mathrm{~nm} \\
{[17.2 \pm 4.6 \mu \mathrm{m}]}\end{array}$ & $\begin{array}{l}25.6 \pm 13.2 \mathrm{~nm} \\
{[5.5 \pm 1.9 \mu \mathrm{m}]}\end{array}$ & $\begin{array}{l}28.4 \pm 12.3 \mathrm{~nm} \\
{[2.6 \pm 0.7 \mu \mathrm{m}]}\end{array}$ & $\begin{array}{l}35.7 \pm 16.8 \mathrm{~nm} \\
\quad[\mathrm{NA}]\end{array}$ \\
\hline ن & 15 & $\begin{aligned} 22.7 \pm 10.7 \mathrm{~nm} \\
{[16.4 \pm 3.8 \mu \mathrm{m}] }\end{aligned}$ & & & & $\begin{array}{c}24.3 \pm 8.4 \mathrm{~nm} \\
{[\mathrm{NA}]}\end{array}$ \\
\hline$\downarrow$ & 18 & $\begin{array}{c}20.3 \pm 7.0 \mathrm{~nm} \\
{[11.3 \pm 3.2 \mu \mathrm{mm}]}\end{array}$ & & & & $\begin{array}{c}\text { NA } \\
\text { [NA] }\end{array}$ \\
\hline
\end{tabular}


Table 2. Summary of TFC-FO thicknesses measured prior to RO testing. The percent compaction of the membrane after testing in RO mode at an applied pressure of 400 psi (27.6 bar) and $25 \pm 0.5^{\circ} \mathrm{C}$ is shown in the square brackets. Values are the average of 3 separately cast membranes.

\begin{tabular}{|c|c|c|c|c|c|c|}
\hline & \multicolumn{5}{|c|}{$\begin{array}{l}\text { Support Layer Thicknesses }(\mu \mathrm{m}) \\
\text { [Compaction after RO Test }(\%)]\end{array}$} \\
\hline & & \multicolumn{5}{|c|}{ DMF Concentration (wt \%) $\longrightarrow$} \\
\hline & & 0 & 25 & 50 & 75 & 100 \\
\hline $\begin{array}{l}20 \\
2 \\
3\end{array}$ & 9 & $\begin{array}{l}141.7 \pm 8.1 \mu \mathrm{m} \\
{[45.2 \%]}\end{array}$ & & & & $\begin{array}{l}92.3 \pm 5.4 \mu \mathrm{m} \\
{[21.4 \%]}\end{array}$ \\
\hline$\frac{.}{\frac{0}{7}}$ & 12 & $\begin{array}{c}144.6 \pm 10.5 \mu \mathrm{m} \\
{[27.1 \%]}\end{array}$ & $\begin{array}{c}124.1 \pm 5.1 \mu \mathrm{m} \\
{[9.0 \%]}\end{array}$ & $\begin{array}{c}105.9 \pm 12.5 \mu \mathrm{m} \\
{[10.7 \%]}\end{array}$ & $\begin{array}{c}97.9 \pm 6.9 \mu \mathrm{m} \\
{[10.0 \%]}\end{array}$ & $\begin{array}{c}84.3 \pm 8.6 \mu \mathrm{m} \\
{[14.1 \%]}\end{array}$ \\
\hline @̊ & 15 & $\begin{array}{c}139.2 \pm 14.2 \mu \mathrm{m} \\
{[9.5 \%]}\end{array}$ & & & & $\begin{array}{c}98.1 \pm 6.2 \mu \mathrm{m} \\
{[16.4 \%]}\end{array}$ \\
\hline$\downarrow$ & 18 & $\begin{array}{c}132.8 \pm 18.8 \mu \mathrm{m} \\
{[6.2 \%]}\end{array}$ & & & & $103.7 \pm 5.2 \mu \mathrm{m}$ \\
\hline
\end{tabular}


Table 3. Summary of Measured FO Water Flux $J_{w}$, NaCl Observed Rejection $R$, and Calculated Structural Parameter $S$, Porosity Parameter $\varepsilon / \tau$, Intrinsic permeability $A$, and $\mathrm{NaCl}$ Permeability Coefficient $B$ for the Membranes Tested ${ }^{\mathrm{a}, \mathrm{b}}$.

\begin{tabular}{|c|c|c|c|c|c|c|c|}
\hline \multicolumn{2}{|c|}{ Membrane } & \multirow{2}{*}{$\begin{array}{l}\text { FO Water } \\
\text { Flux } J_{w} \\
\left(\mathrm{~L} \mathrm{~m}^{-2} \mathrm{~h}^{-1}\right)\end{array}$} & \multirow{2}{*}{$\begin{array}{l}\text { Structural } \\
\text { Parameter } \\
S \\
(\mu \mathrm{m})\end{array}$} & \multirow{2}{*}{$\begin{array}{l}\text { Porosity } \\
\text { Parameter } \\
\varepsilon / \tau \\
\left(\mathrm{L} \mathrm{m}^{-2} \mathrm{~h}^{-1}\right)\end{array}$} & \multirow{2}{*}{$\begin{array}{l}\text { Intrinsic } \\
\text { Permeability } A \\
\left(\mathrm{~L} \mathrm{~m}^{-2} \mathrm{~h}^{-1} \text { bar }^{-1}\right)\end{array}$} & \multirow{2}{*}{$\begin{array}{l}\mathrm{NaCl} \\
\text { Permeability } \\
\text { Coefficient } B \\
\left(\mathrm{~L} \mathrm{~m}^{-2} \mathrm{~h}^{-1}\right)\end{array}$} & \multirow{2}{*}{$\begin{array}{l}\mathrm{NaCl} \\
\text { Rejection } \\
R \\
(\%)\end{array}$} \\
\hline $\begin{array}{l}\text { PSf } \\
\text { Concentration } \\
\text { (wt \%) }\end{array}$ & $\begin{array}{l}\text { DMF } \\
\text { Concentration } \\
\text { (wt \%) }\end{array}$ & & & & & & \\
\hline 9 & 0 & $20.5 \pm 3.8$ & $389 \pm 150$ & $0.222 \pm 0.088$ & $1.63 \pm 0.18$ & $0.84 \pm 0.19$ & $95.8 \pm 1.3$ \\
\hline 12 & 0 & $13.9 \pm 1.0$ & $530 \pm 48$ & $0.201 \pm 0.022$ & $1.04 \pm 0.17$ & $0.63 \pm 0.20$ & $96.7 \pm 1.4$ \\
\hline 15 & 0 & $9.2 \pm 0.2$ & $964 \pm 301$ & $0.140 \pm 0.046$ & $0.97 \pm 0.44$ & $0.25 \pm 0.12$ & $96.8 \pm 3.1$ \\
\hline 18 & 0 & $6.2 \pm 2.8$ & $2677 \pm 2189$ & $0.064 \pm 0.033$ & $1.09 \pm 0.06$ & $0.47 \pm 0.29$ & $97.2 \pm 1.0$ \\
\hline 12 & 25 & $10.8 \pm 2.4$ & $676 \pm 111$ & $0.163 \pm 0.032$ & $0.93 \pm 0.37$ & $0.52 \pm 0.29$ & $97.3 \pm 1.0$ \\
\hline 12 & 50 & $12.5 \pm 1.0$ & $577 \pm 108$ & $0.166 \pm 0.014$ & $0.93 \pm 0.24$ & $0.27 \pm 0.03$ & $97.7 \pm 0.4$ \\
\hline 12 & 75 & $14.3 \pm 2.5$ & $545 \pm 77$ & $0.155 \pm 0.020$ & $1.17 \pm 0.23$ & $0.42 \pm 0.16$ & $97.9 \pm 0.6$ \\
\hline 9 & 100 & $25.0 \pm 4.1$ & $312 \pm 72$ & $0.264 \pm 0.087$ & $1.90 \pm 0.30$ & $0.33 \pm 0.19$ & $98.6 \pm 0.8$ \\
\hline 12 & 100 & $17.6 \pm 0.4$ & $502 \pm 59$ & $0.140 \pm 0.029$ & $1.75 \pm 0.35$ & $0.33 \pm 0.14$ & $98.5 \pm 0.3$ \\
\hline 15 & 100 & $5.6 \pm 1.6$ & $2511 \pm 1168$ & $0.036 \pm 0.013$ & $1.05 \pm 0.05$ & $0.84 \pm 0.19$ & $99.3 \pm 0.3$ \\
\hline 18 & 100 & $0.5 \pm 0.1$ & $7934 \pm 1051$ & $0.012 \pm 0.002$ & $0.66 \pm 0.39$ & $0.84 \pm 0.19$ & $96.2 \pm 2.5$ \\
\hline \multicolumn{8}{|c|}{ PET Not Wetted } \\
\hline 12 & 0 & $5.4 \pm 0.6$ & $2232 \pm 447$ & $0.040 \pm 0.008$ & $0.92 \pm 0.06$ & $0.13 \pm 0.06$ & $99.2 \pm 0.4$ \\
\hline 15 & 0 & $\begin{array}{r}\text { Below } \\
\text { Detection } \\
\text { Limit }\end{array}$ & NA & NA & 0.13 & 0.10 & 94.6 \\
\hline Higher Ca & $\begin{array}{r}\text { ting Thickness } \\
\text { (height) }\end{array}$ & & & & & & \\
\hline 12 & 0 (20 mils) & 5.6 & 2563 & 0.057 & 1.41 & 0.20 & 99.0 \\
\hline
\end{tabular}

a The experimental conditions are stated in the manuscript.

${ }^{\mathrm{b}}$ For the recipes illustrated in Figure 1 an average of 3 separately cast membranes is reported with standard deviation, except for the membranes cast at 18\% PSf in 100\% DMF, whose values represent the average and standard deviation of 2 separately cast membranes. 


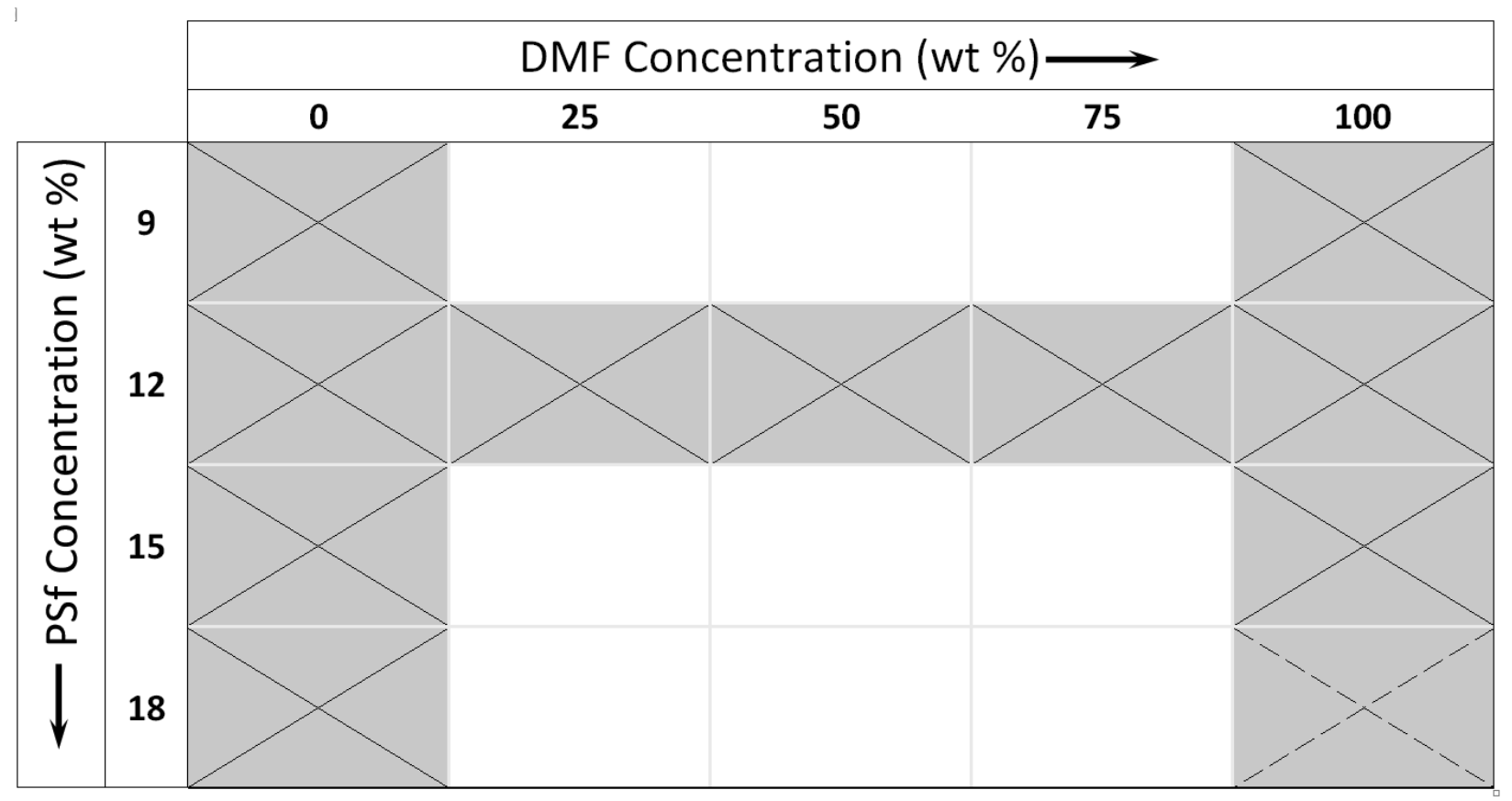

Figure 1. Summary of the different recipes employed in the fabrication of the PSf support layers. The columns represent different NMP and DMF mixtures, with the DMF concentration increasing from left to right. Namely, the DMF concentrations are 0, 25, 50, 75, and $100 \mathrm{wt} \%$ (based only on the solvent masses) for columns 1 through 5, respectively. The rows represent different PSf concentrations increasing down the column. The PSf concentrations are 9, 12, 15, and $18 \mathrm{wt} \%$ for rows 1 through 4, respectively. The investigated recipes are highlighted in grey and crossed. The cell corresponding to $18 \mathrm{wt} \%$ PSf concentration in 100\% DMF is crossed using a dash line because the related data is incomplete as explained in the discussion. 

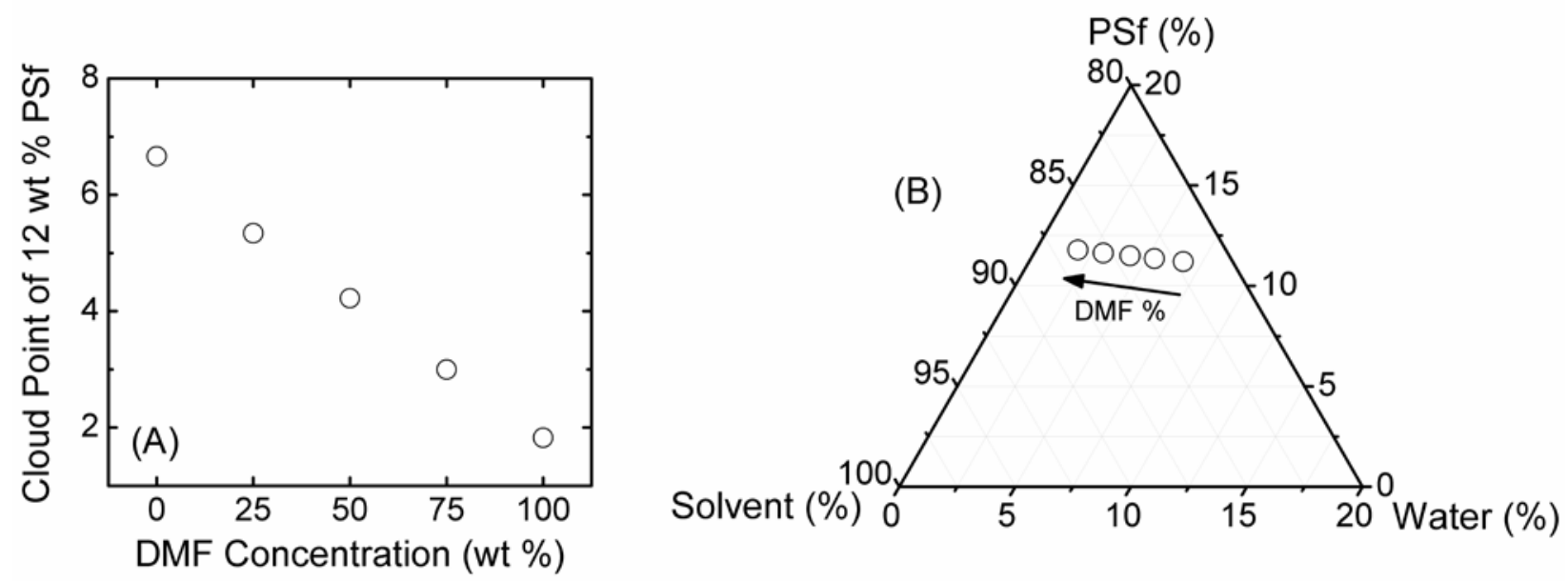

Figure 2. Plot of (A) the observed cloud points of $12 \%$ PSf and (B) related binodal points in the ternary diagram as a function of DMF concentration in the dope solution. Cloud point is calculated as the amount of nonsolvent (DI water) added to the dope to turn it turbid, expressed in wt \% with respect to the polymer solution plus the nonsolvent. 


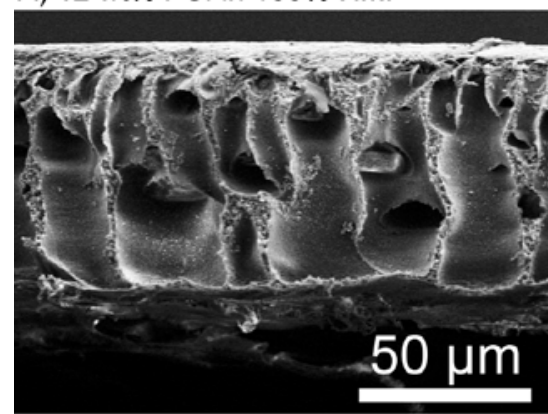

D) $12 \mathrm{wt} \% \mathrm{PSf}$ in $75 \% \mathrm{DMF}$

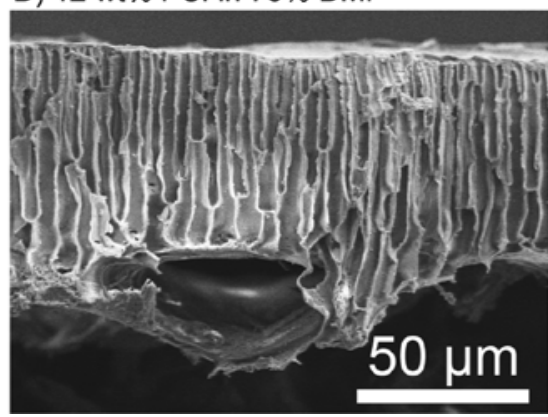

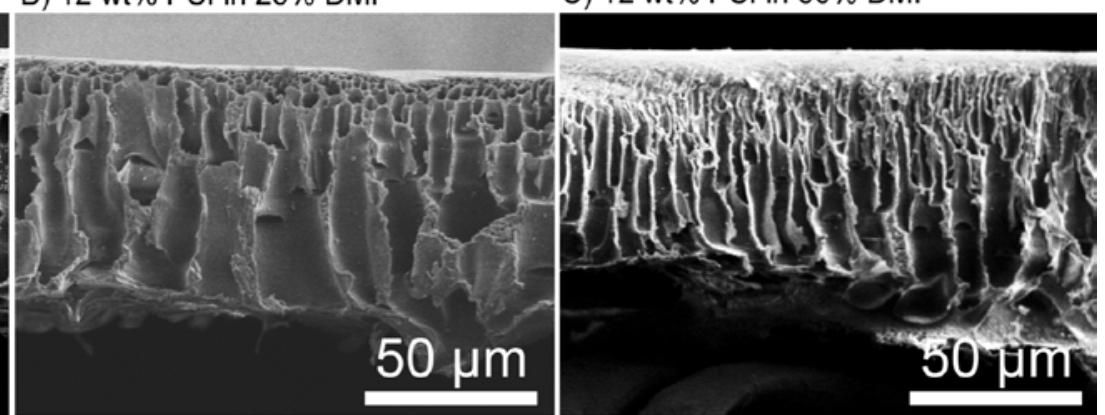

E) $12 w t \% \mathrm{PSf}$ in $100 \% \mathrm{DMF}$

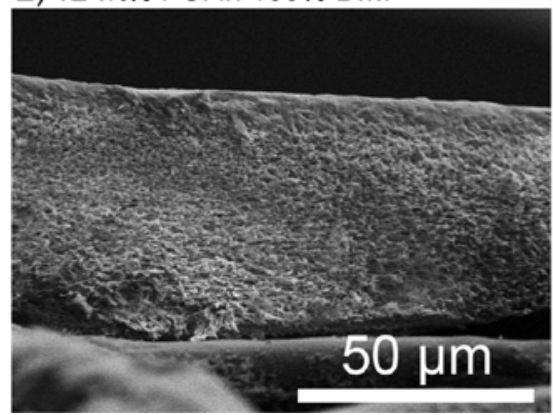

Figure 3. SEM micrographs displaying the cross-section of membranes cast at a fixed PSf concentration (12 wt \%) and increasing DMF concentrations: (A) 0, (B) 25, (C) 50, (D) 75, and (E) $100 \%$. 

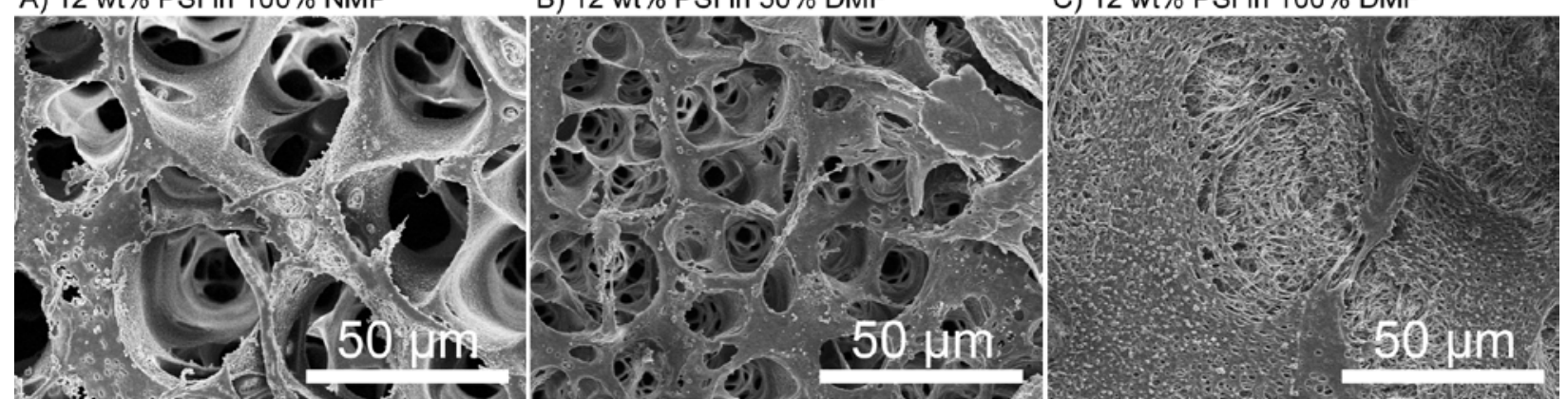

Figure 4. SEM micrographs displaying the bottom surface membranes cast at a fixed PSf concentration (12 wt \%) and increasing DMF concentrations: (A) 0, (B) 50, and (C) 100\%. For all samples, the PET non-woven fabric was carefully removed prior to imaging. 
A) 9 wt $\%$ PSf in $100 \%$ NMP

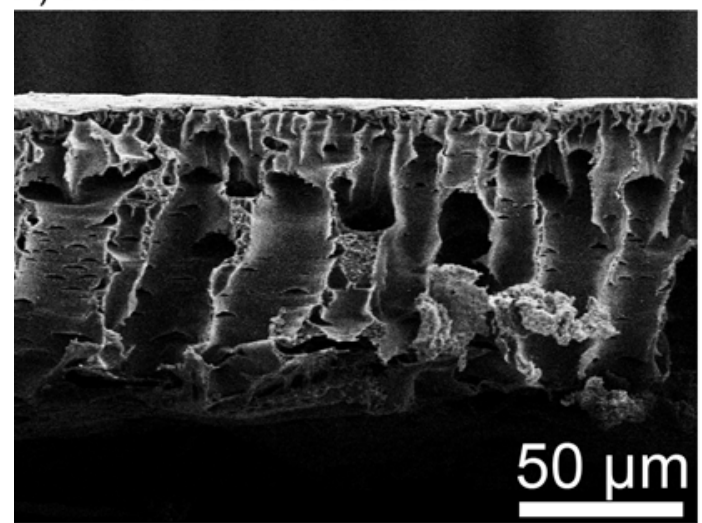

B) $15 \mathrm{wt} \% \mathrm{PSf}$ in $100 \% \mathrm{NMP}$

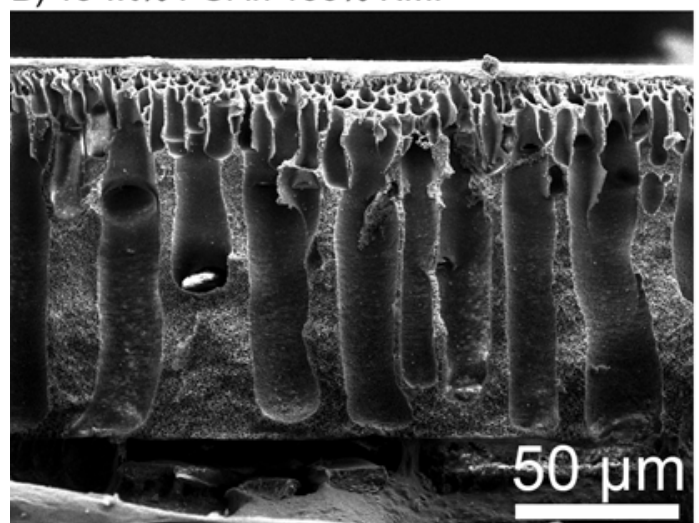

C) $18 \mathrm{wt} \% \mathrm{PSf}$ in $100 \% \mathrm{NMP}$

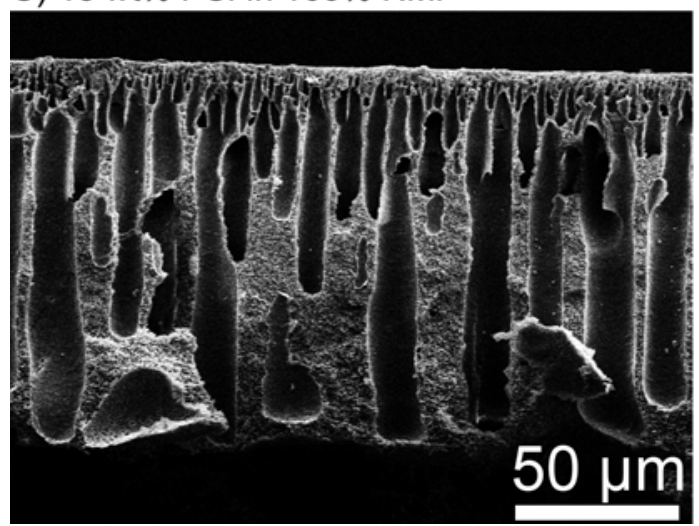

D) $9 w t \%$ PSf in $100 \%$ DMF

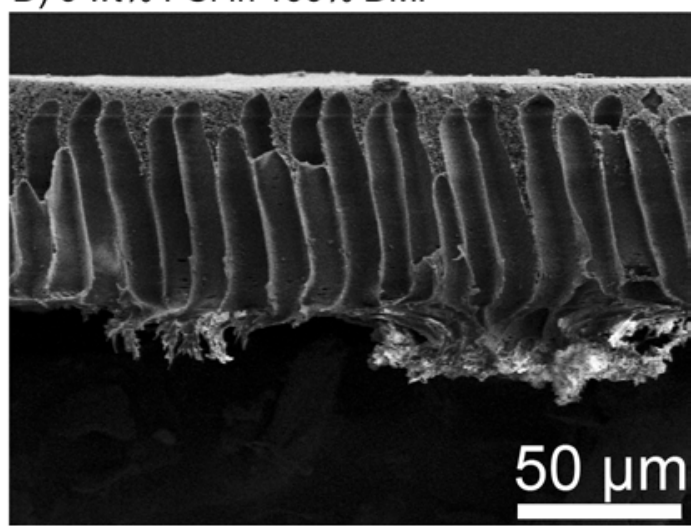

E) $15 w t \%$ PSf in $100 \%$ DMF

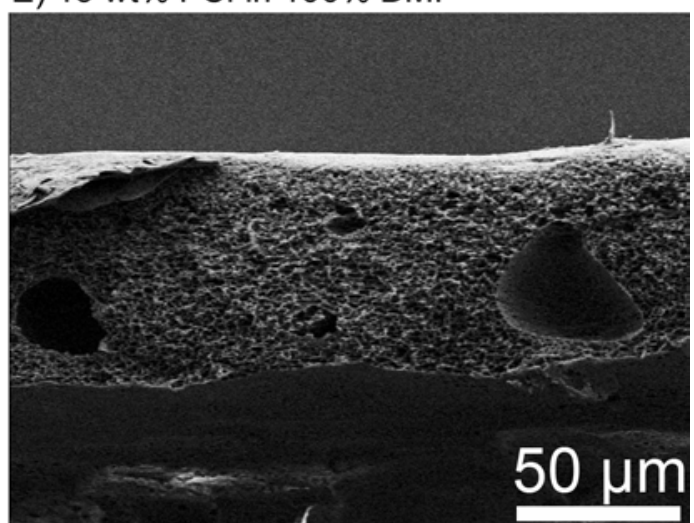

F) $18 w t \%$ PSf in $100 \%$ DMF

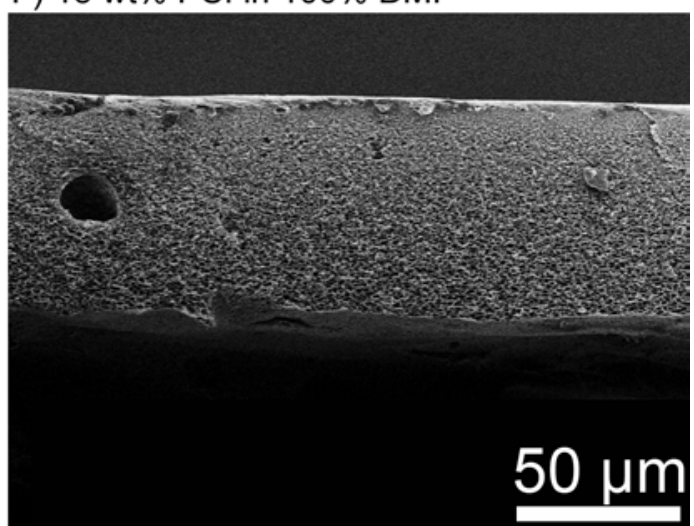

Figure 5. SEM micrographs displaying the cross-section of support membranes cast from (A, D) 9, (B, E) 15, and (C, F) 18 wt \% PSf concentration in 100\% NMP or DMF solvent. The micrographs in the left column were cast from 100\% NMP, whereas the right column of micrographs relates to membranes cast from 100\% DMF. 


\section{A) $15 w t \%$ PSf in $100 \%$ NMP}

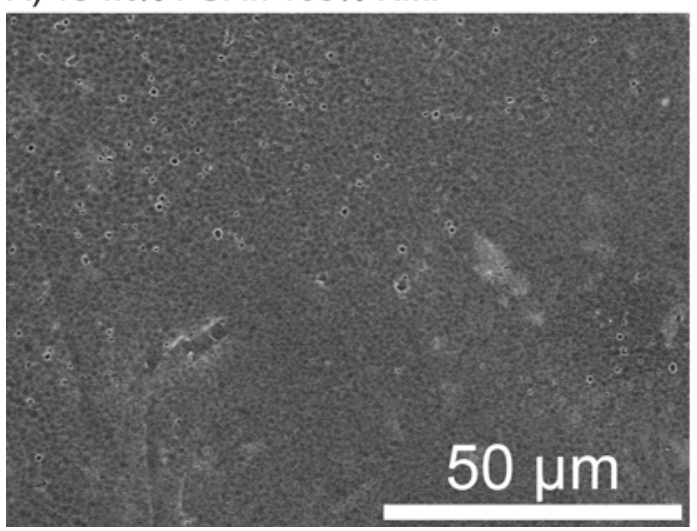

B) $15 w t \%$ PSf in $100 \% \mathrm{NMP}$

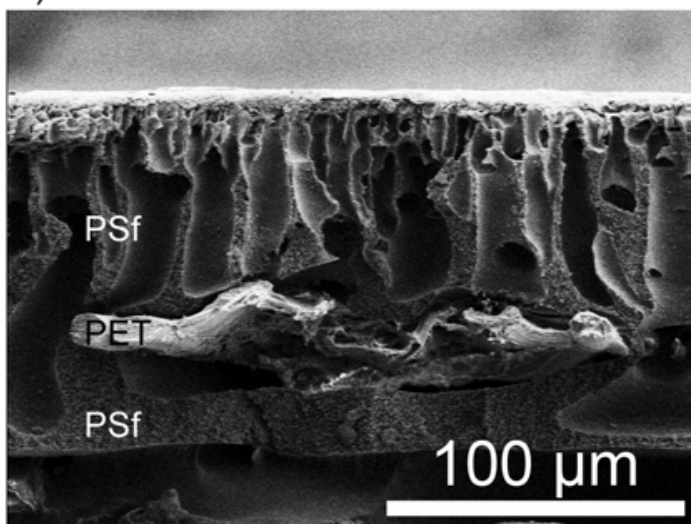

Figure 6. SEM micrographs displaying the (A) bottom and (B) cross-section of membranes cast onto non-wetted PET fabric fabricated from 15 wt \% PSf in 100\% NMP solvent. The PET fabric was not removed for the imaging of (A) or (B). 


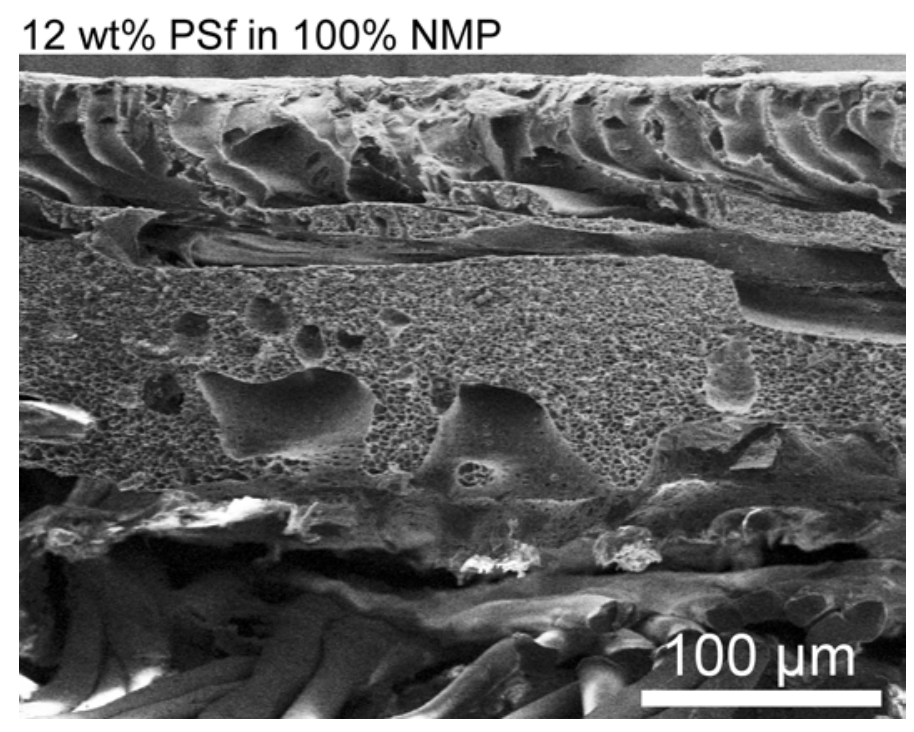

Figure 7. SEM micrograph displaying the cross-section of a support membrane cast from 12 wt \% PSf in $100 \%$ NMP solvent that was cast at a blade height of 20 mils yielding a $266 \pm 12$ $\mu \mathrm{m}$ thick membrane. Note: $1 \mathrm{mil}$ is equivalent to 0.001 inch or $25.4 \mu \mathrm{m}$. 

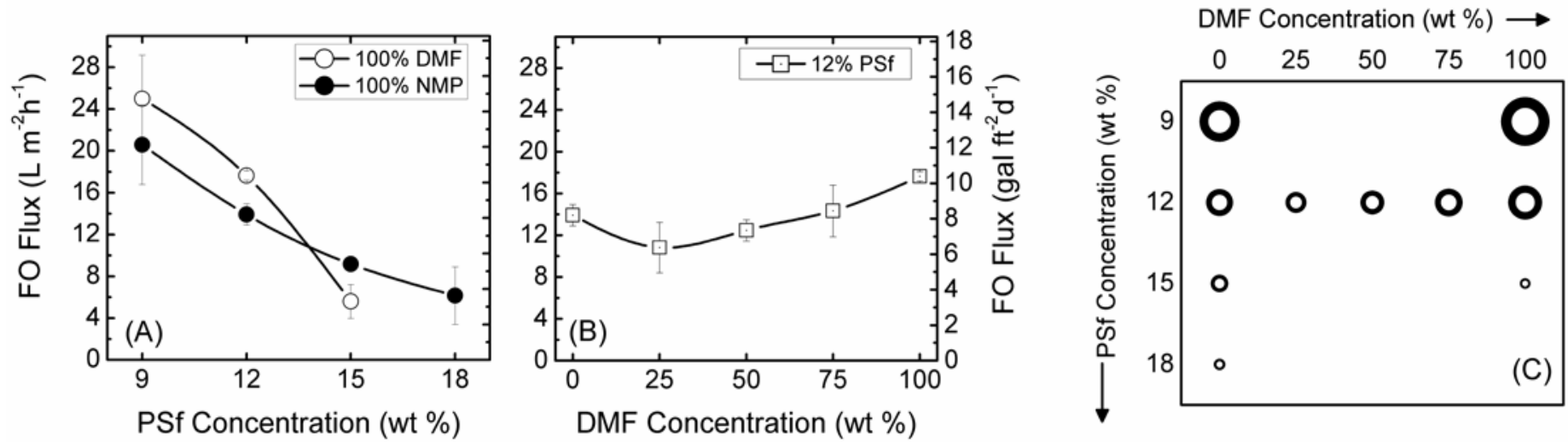

Figure 8. Comparison of FO water fluxes between the different TFC FO membranes cast in this study. (A) Water flux for membranes cast with varying PSf concentration in either all DMF or all NMP solvent. (B) Water flux for membranes cast at fixed PSf concentration (12 wt \%) and varying the NMP and DMF solvent mixture. (C) Bubble graph summarizing the data, where the size of each bubble is proportional to the FO flux value for each related membrane in the matrix. Data points are the average of 3 separately cast membranes, with error bars representing standard deviations. A line connecting data points is drawn only to guide the eye. Experimental conditions for FO flux were as follows: $1 \mathrm{M} \mathrm{NaCl}$ draw solution, DI feed solution, and feed and draw solution temperature of $25^{\circ} \mathrm{C}$. A value for membranes cast at $18 \mathrm{wt} \% \mathrm{PSf}$ in $100 \% \mathrm{DMF}$ is not included because the results were not reproducible enough to be considered statistically significant; however, the average FO flux of two separately cast membranes was $1.9 \mathrm{~L} \mathrm{~m}^{-2} \mathrm{~h}^{-1}$ (1.1 gal $\left.\mathrm{ft}^{-2} \mathrm{~d}^{-1}\right)$. 

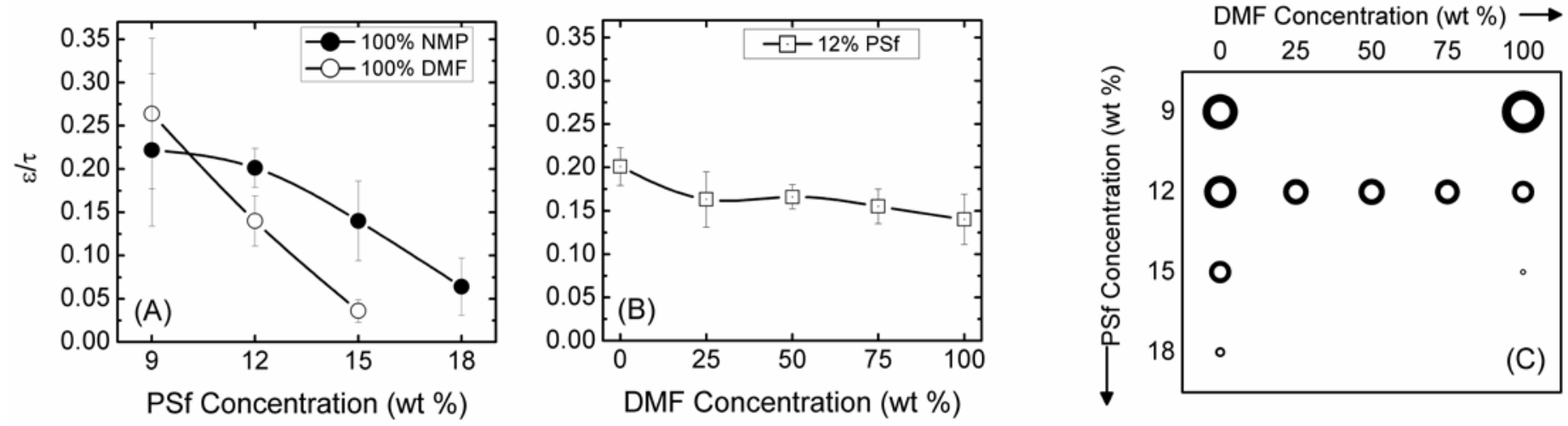

Figure 9. Comparison of calculated porosity parameter $\varepsilon / \tau$ between the different TFC FO membranes cast in this study. (A) Porosity data for membranes cast varying PSf concentration in either all DMF or all NMP solvent. (B) Porosity data for membranes cast at fixed PSf concentration (12 wt \%) and varying the NMP and DMF solvent mixture. (C) Bubble graph summarizing the data, where the size of each bubble is proportional to the porosity parameter value for each related membrane in the matrix. Data points are the average of 3 separately cast membranes, with error bars representing standard deviations. A line connecting data points is drawn only to guide the eye. The porosity parameter is calculated using equation Error! Reference source not found. and isolating the effect of membrane thickness. A value for membranes cast at $18 \mathrm{wt} \%$ PSf in $100 \%$ DMF is not included because the results were not reproducible enough to be considered statistically significant: however, the average calculated porosity parameter of two separately cast membranes was 0.012 . 

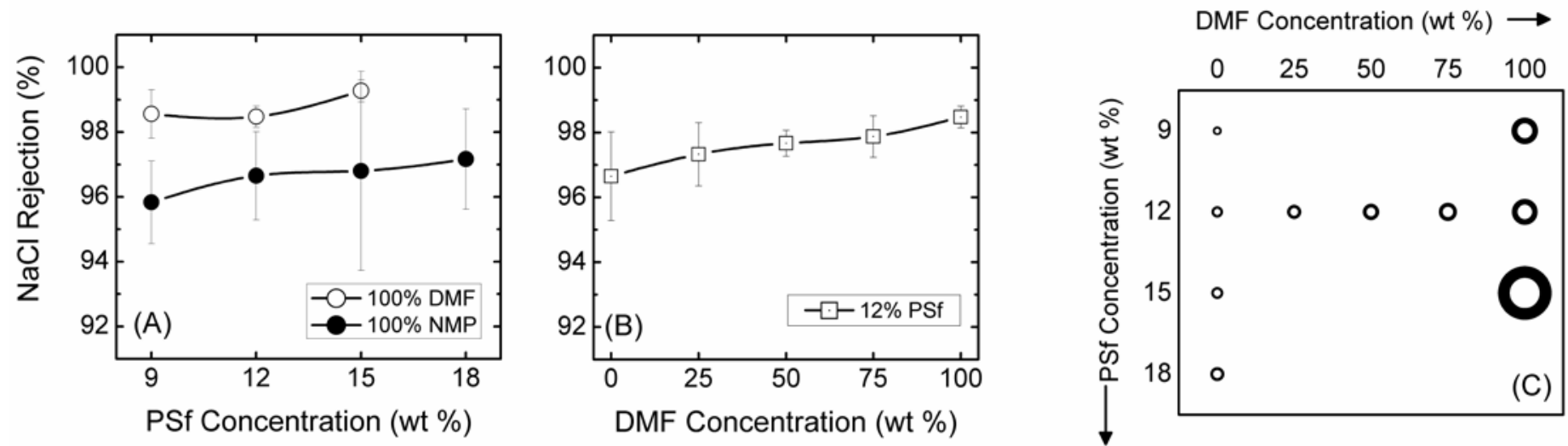

Figure 10. Comparison of observed $\mathrm{NaCl}$ rejection between the different TFC FO membranes cast in this study, measure in RO. (A) Salt rejection for membranes cast by varying PSf concentration in either all DMF or all NMP solvent. (B) Salt rejection for membranes cast at fixed PSf concentration (12 wt \%) and varying the NMP and DMF solvent mixture. (C) Bubble graph summarizing the data, where the size of each bubble is proportional to the $1 /(1-R)$ value, or inverse of the salt passage, for each related membrane in the matrix. Data points are the average of 3 separately cast membranes, with error bars representing standard deviations. A line connecting data points is drawn only to guide the eye. Conditions for rejection experiments were as follows: $50 \mathrm{mM} \mathrm{NaCl}$ feed solution, 400 psi (27.6 bar) applied pressure, cross-flow of $21.4 \mathrm{~cm} / \mathrm{s}$, and temperature of $25{ }^{\circ} \mathrm{C}$. A value for membranes cast at 18 wt \% PSf in 100\% DMF is not included because the results were not reproducible enough to be considered statistically significant: however, the average observed $\mathrm{NaCl}$ rejection of two separately cast membranes was $96.2 \%$. 


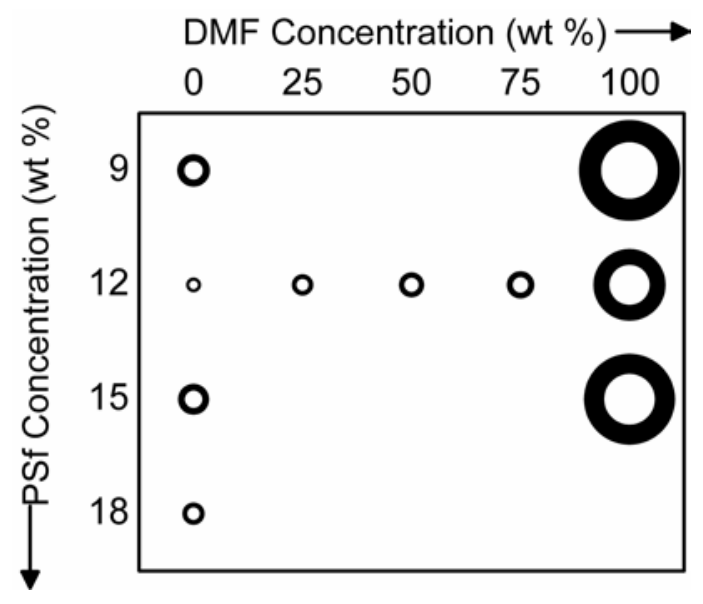

Figure 11. Bubble graph of $A^{2} / B$ for the different TFC FO membranes cast in this study, as measured from RO experiments, with $A$ being the pure water intrinsic permeability and $B$ the salt permeability coefficient. Data points are the average of 3 separately cast membranes. RO experimental conditions were as follows: $50 \mathrm{mM} \mathrm{NaCl}$ feed solution, 400 psi (27.6 bar) applied pressure, cross-flow of $21.4 \mathrm{~cm} / \mathrm{s}$, and temperature of $25{ }^{\circ} \mathrm{C}$. A value for membranes cast at 18 wt \% PSf in $100 \%$ DMF is not included because the results were not reproducible enough to be considered statistically significant. 